\title{
A Regulatory Policy Strategy for Protecting Immigrant Workers*
}

\author{
W. Kip Viscusi ${ }^{* *} \&$ Nick Marquiss ${ }^{* * *}$
}

Immigration has become a focal point of many political campaigns, most notably that of President Trump in 2016 and again in 2020. Populist rhetoric also decries immigrant workers for taking Americans' jobs and depressing wages for U.S.-born workers. Yet immigrants serve a constructive role by working in some of the most dangerous occupations in the country. It is well-known that immigrant workers, particularly those from Mexico with limited English language skills, face a higher workplace fatality rate than native workers. Efforts to reverse this trend have long been the focus of the Occupational Safety and Health Administration (OSHA), which undertook numerous policy initiatives under the Bush and Obama Administrations to reduce immigrant fatalities in the workplace.

Using three different datasets, this Article empirically shows that, while job safety has improved for immigrant workers, more gains are required to reduce immigrant fatality rates to align with those of native workers. In reaching this result, we make several contributions to the literature. First, we use recent data from the Census of Fatal Occupational Injuries (CFOI) to show that immigrants, particularly those from Mexico, experienced higher fatality rates than native-born workers in 2003, 2007, and 2015. Second, we empirically demonstrate that a large group of recent immigrants to the United States, as reported in the New Immigrant Survey, either remain in high-risk jobs or increase their fatality risks over time. In doing so, we are the first researchers to exploit the longitudinal nature of the New Immigrant Survey to assess whether immigrant workers progressed into safer jobs between 2003 and 2007. Finally, we

*This paper used fatal injury data that were obtained with restricted access to the Bureau of Labor Statistics' (BLS) Census of Fatal Occupational Injuries (CFOI) Research File.

${ }^{* *}$ University Distinguished Professor of Law, Economics, and Management, Vanderbilt Law School, 131 21st Ave. South, Nashville, TN 37203, (615) 343-7715, kip.viscusi@vanderbilt.edu.

***Vanderbilt Law School, Ph.D. Program in Law and Economics, nicholas.m.marquiss@vanderbilt.edu. 
provide updated estimates of the Value of Statistical Life for immigrant workers using recent fatality data from the 2015 CFOI. Here, we show that unlike native-born workers, immigrant workers-especially those from Mexico-are not only in higher-risk jobs but also not compensated with hazard pay for workplace fatality risks.

In conjunction, these results show that, while OSHA's outreach programs toward immigrants have served a constructive function, more can be done to communicate job risks to immigrant workers to help them progress into safer jobs. In particular, since immigrant workers who lack English proficiency suffer most in the labor market, we recommend that OSHA target its outreach programs toward providing safety materials in an immigrant worker's native language to alert workers to the hazards that are present and to promote safety training that immigrant workers can understand. Additionally, we also suggest that OSHA conduct a benefit-cost analysis to assess alternative regulatory policies that mandate employers to provide safety and training materials in other languages, such as Spanish.

I. INTRODUCTION 935

II. BACKGROUND

A. Broad Summary of Immigrant Characteristics 941

B. Immigrant Distribution in the Labor Force...............................943

III. COMPARING RISK LEVELS FOR IMMIGRANTS AND NATIVE WORKERS......... 945

A. Construction of Fatality Rates .................................................... 945

B. Comparing Immigrant and Native Risk Levels.

1. Ratio of Immigrant Fatalities to Share of the Workforce

2. Comparing Immigrant and Native Fatality Rates............949

C. Immigrants Remain in High-Risk Jobs over Time ................... 951

IV. Do IMMIGRANTS GET PAID FOR RISKY JOBS? THEORY OF THE VSL ........... 959

A. What is the VSL? ...................................................................... 960

B. Theoretical Derivation of the VSL .............................................960

C. The VSL for Immigrant Workers................................................. 962

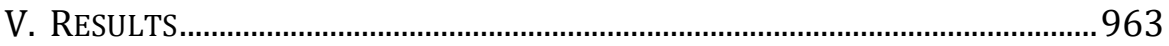

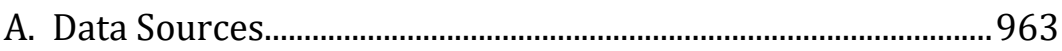

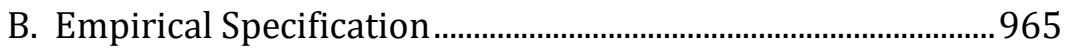

C. Results in the Previous Literature ............................................966

D. New Estimates of Immigrant's Failure to Receive Hazard Pay

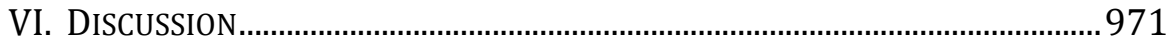

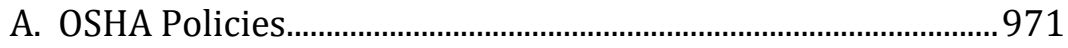

1. Immigrant Outreach Programs..............................................972 


\section{INTRODUCTION}

Immigration has become a focal point of many political campaigns, most notably that of President Trump in 2016 and again in 2020.1 In addition, populist rhetoric decries immigrants for "taking American jobs" and depressing wages for U.S.-born workers. ${ }^{2}$ Yet, despite these notions, it is also the case that immigrants serve a constructive function for the U.S. economy through their work in some of the most dangerous occupations in the country. In 2018, immigrants disproportionately worked in the farming, fishing, forestry, and construction occupations relative to U.S.-born workers, ${ }^{3}$ which are among the country's most dangerous occupations. ${ }^{4}$ On average, immigrant workers, particularly those from Mexico, also have a higher workplace fatality rate than native-born workers. ${ }^{5}$

The fact that immigrants face higher workplace mortality risks has not gone unnoticed by academics or policymakers. The Occupational Safety and Health Administration (OSHA), which is tasked with protecting both U.S.-born and immigrant workers in their workplaces, has engaged in many outreach or educational programs to reduce

1 Making America Great Again: Immigration / President Donald Trump Accomplishments, PROMISES MADE, Promises KePT!, https://www.promiseskept.com/ achievement/overview/immigration [https://web.archive.org/web/202001020426 09/https://www.promiseskept.com/achievement/overview/immigration/] (last visited Jan. 2, 2020); Daniel Bush, Where President Trump Stands on the Issues in 2020, PBS NEws Hour (June 19, 2019, 5:16 PM), https://www.pbs.org/newshour/politics/ where-president-trump-stands-on-the-issues-in-2020 (last visited Jan. 16, 2020).

2 Josh Boak, AP Fact Check: Trump Plays on Immigration Myths, PBS News Hour (Feb. 8, 2019, 10:44 AM), https://www.pbs.org/newshour/politics/ap-fact-check-trumpplays-on-immigration-myths (quoting President Trump as saying, "[w]orking-class Americans are left to pay the price for mass illegal immigration: reduced jobs, lower wages, overburdened schools, hospitals that are so crowded you can't get in, increased crime, and a depleted social safety net").

3 Census of Fatal Occupation Injuries (CFOI)--Current and Revised Data, U.S. BuREAU of LABOR STATISTICS, https://www.bls.gov/iif/oshcfoi1.htm\#rates (last visited Jan. 15, 2020).

4 Id.

5 See generally Joni Hersch \& W. Kip Viscusi, Immigrant Status and the Value of Statistical Life, 45 J. HumAn Res. 749 (2010). 
immigrant fatalities on the job site. ${ }^{6}$ Likewise, many academics have demonstrated empirically that immigrants on average experience a higher workplace fatality rate than U.S.-born workers and, more concerning, that some groups of immigrants receive little or no compensation for these job risks. ${ }^{7}$ In light of OSHA's efforts to address immigrant fatalities along with the academic research showing that immigrants fare poorly in the workplace, this Article offers an updated picture of workplace fatality risks for immigrants. In doing so, this Article provides new empirical evidence that immigrants experience higher average fatality risks than U.S.-born workers, that many immigrants fail to progress into safer jobs over time, and that immigrant workers, especially those from Mexico, are not compensated through hazard pay for their job risks. This Article, therefore, serves not only as an update to results in the economics literature but also provides insight into the effectiveness of OSHA's efforts to reduce immigrant fatalities. In addition, this Article is the first to demonstrate that many immigrants fail to transition to safer jobs over time using data from the New Immigrant Survey (NIS).

This Article proceeds as follows. Part II provides contextual demographic information about the immigrant population in the United States before concluding by showing that immigrants disproportionately work in the most dangerous occupations in the United States.

Part III shows that immigrants experience higher average fatality rates than U.S.-born workers and that many immigrants remain locked into high-risk jobs over time. To conduct this analysis, we first explain our procedure for the construction of fatality rates using the CFOI dataset in Section III.A. We then apply the fatality rates in Section III.B to data from the Current Population Survey (CPS) to show that immigrants bear a disproportionate share of workplace fatalities and have a higher average fatality rate than U.S.-born workers. Finally, Section III.C concludes by using data from the NIS to empirically demonstrate that a substantial portion of new immigrants in the United States remained in high-risk jobs between the two waves of the NIS.

6 See infra Section VI.A.

7 Christen G. Byler, Hispanic/Latino Fatal Occupational Injury Rates, MonTHLY LaB. REv., Feb. 2013 at 14; Hersch \& Viscusi, supra note 5, at 749; Pia M. Orrenius \& Madeline Zavodny, Do Immigrants Work in Riskier Jobs?, 46 DEMOGRAPHY 535 (2009); Scott Richardson, et al., Appendix D: Hispanic Workers in the United States: An Analysis of Employment Distributions, Fatal Occupational Injuries, and Non-Fatal Occupational Injuries and Illnesses, in SAFETy IS SEguridad: A Workshop Summary 43, 43 (Nat'l Rsch. Council, 2003); Katherine Loh \& Scott Richardson, Foreign-Born Workers: Trends in Fatal Occupational Injuries, 1996-2001, Monthly LAB. REV., Oct. 2005, at 42, 42. 
Of course, showing that immigrants experience a higher average fatality risk than native-born workers or remain locked into high-risk jobs is only part of the story, since it may be the case that immigrants simply prefer high-risk jobs. We must therefore ask whether immigrants receive wage compensation in return for their aboveaverage job risks. Before answering this question empirically, we first describe in Part IV how it is theoretically possible for immigrants and native workers to be paid differently for job risks for the same job. In short, we explain that immigrants and U.S.-born workers can receive different wage compensation for job risks if the labor market is segregated so that immigrants face a different set of job options than do non-immigrants. ${ }^{8}$ Put another way, the available wage rate offered in the market for any given level of risk differs for native and immigrant workers. Accordingly, immigrant workers may select a high-risk job from the options available to them, but they may not receive the same level of wage compensation for these risks that other workers who face a different wage-offer curve receive. Part IV also provides background information on the Value of a Statistical Life (VSL), which quantifies the benefit of avoiding a fatality, for our VSL estimations in Part V.

Part V provides our primary results. This Part first outlines the data and methodology used to show that immigrants do not receive hazard pay and describes other results in the literature that also illustrate that immigrants are not compensated for job risks. This Part then provides our empirical estimates and reports our primary result that immigrant workers, particularly those from Mexico, fail to receive hazard pay for their fatality risks. We show that in 2015 this failure, on average, cost immigrants over $\$ 500$ in lost annual wages and that Mexican immigrants were underpaid by nearly $\$ 1,000$ annually because they did not receive compensation for job risks. ${ }^{9}$ The results in this Part, in conjunction with those developed in Part III, complete the picture of immigrants in the workforce: immigrants face a higher average fatality rate than native workers, remain locked into high-risk jobs over time, and, in the case of Mexican immigrants, do not receive adequate wage compensation for their fatality risk.

Part VI outlines our policy recommendations that OSHA can undertake to reduce immigrant fatalities. This Part begins by summarizing OSHA's policies toward the immigrant-worker population in the United States. In particular, Section VI.A documents that OSHA's interest in improving immigrant workers' welfare in the labor force

8 Hersch \& Viscusi, supra note 5, at 752.

9 See infra Section V.D. 
dates back to the George W. Bush administration, ${ }^{10}$ grew under the Barack Obama administration,11 and continued, though perhaps with less force, under the Donald Trump administration.12 Part VI next discusses our results in light of OSHA's policies to reduce immigrant workplace fatalities and makes several policy recommendations regarding how OSHA can increase immigrant-worker safety.

Overall, the results developed in this Article show that OSHA could have done more to improve immigrant welfare in the workplace under the Bush and Obama Administrations. ${ }^{13}$ First, immigrant fatality rates were roughly the same in 2003 and 2007-a period that spans OSHA's outreach programs under the Bush Administration. To be sure, OSHA's policies at this time may have prevented immigrant fatality rates from being higher than they would have been absent OSHA's efforts. Nevertheless, immigrant workers failed to improve relative to U.S.-born workers-as evidenced by the fact that both immigrant-worker fatality rates and U.S.-born-worker fatality rates were constant. This persistent fatality rate gap creates potential opportunities for government policies to improve workplace safety for immigrant workers to be comparable to that of native American workers.

In addition to the lack of progress in immigrant safety at the economy-wide level, individual workers also failed to progress into safer jobs over time. We show that from 2003 to 2007 immigrants remained locked into high-risk jobs and immigrant workers, especially Mexican immigrants, did not receive hazard pay for their higher job risks. Under the Bush Administration, OSHA engaged in several community outreach programs to improve immigrant welfare, including the creation of a national clearinghouse for training programs in Spanish, a Spanish-language website for employees and employers, the establishment of an 800 number for Spanish-speaking workers, and

10 See, e.g., John L. Henshaw, Assistant Sec'y of Lab, Dep't of Lab., Statement before the Subcommittee on Employment, Safety and Training (Feb. 27, 2002), https://www.osha.gov/news/testimonies/02272002 (explaining the creation of the Hispanic Worker's Task Force).

11 Press Release, Dep't of Lab., National Action Summit for Latino Worker Health \& Safety (Apr. 14-15, 2010), https://www.osha.gov/archive/latinosummit/index.html (outlining the creation of a summit to discuss Latino worker safety).

12 See, e.g., Training Resources in Spanish Language, OCCuPATIONAL SAFETY AND HEALTH ADMIN., https://www.osha.gov/dte/outreach/construction_generalindustry/spanish_ training.html (last visited Jan. 13, 2020) (providing training resources for Spanishspeaking workers); Annual Alliance Report, Occupational SafETy and Health Admin., https://www.osha.gov/alliances/regional/region6/alliance-annual-report_20190726 (last visited Jan. 13, 2020) (outlining OSHA's outreach programs in Texas under the Trump Administration).

13 We narrow our focus to the Bush and Obama Administrations, rather than the Trump Administration as well, because our data only span these two administrations. 
several local outreach programs to distribute safety materials in Spanish. Though these programs appear to be constructive efforts that are well-suited to addressing the obstacles posed by language barriers, more vigorous and effective efforts are needed.

In addition, our results also suggest that, while OSHA's outreach efforts under the Obama Administration seemed to be well-suited to enhancing immigrant workers' welfare, they were inadequate by themselves to eliminate the labor market challenges facing immigrant workers. Notably, in 2010, OSHA organized a national summit with over five hundred attendees-such as labor union members and community leaders - to address immigrant fatalities, particularly in the Latino community. Follow-up summits held across the country emerged after the national summit to develop ways to provide immigrant workers with education, training, and assistance. Conferences such as these provide an alert regarding immigrants' higher job risks, but they were ultimately insufficient to improve immigrant outcomes nationwide. We show that immigrant workers still suffered in the labor market relative to native workers between 2007 and 2015. For instance, Section III.B shows that the fatality rate for immigrants was higher than U.S.-born workers in 2007 and 2015, and Section V.D shows that immigrants, especially those from Mexico, did not receive hazard pay for bearing these risks during this time. Again, it may be the case that but for OSHA's policies, the picture for immigrants could be even bleaker than it already is. Even so, our data does not show that the safety and risk compensation of immigrant workers improved relative to native workers: U.S.-born workers had a lower fatality rate than immigrants and, unlike immigrants, received hazard pay for job risks in 2007 and 2015 , suggesting that immigrants did not improve relative to U.S.-born workers.

OSHA engaged in many outreach efforts toward immigrant workers under both the Bush and Obama Administrations, such as the creation of the Hispanic Worker's Task Force in 2002 and the National Action Summit for Latino Worker Health \& Safety in 2010. While these programs seem quite appropriate, we think that the continued immigrant-native worker gap in labor market outcomes with respect to risk levels and risk compensation creates opportunities to narrow this gap. Based on prior research showing that immigrants not fluent in English suffer relative to immigrants more adept in English, ${ }^{14}$ we make a modest recommendation that, so long as the programs' benefits exceed their costs, OSHA engage in more targeted programs aimed at

\footnotetext{
14 Hersch \& Viscusi, supra note 5, at 768.
} 
delivering safety materials to immigrant workers in their native language. Focusing on Spanish-speaking immigrant workers is an ideal starting point, given that Mexican workers face the highest fatality risk levels and receive no corresponding compensation in wages. Through initiatives like this, OSHA can educate immigrant workers that lack English skills about the job risks that they face in their workplaces and the precautions that they might take to reduce these risks. This could then encourage immigrant workers to transition into safer jobs-or at least jobs that will compensate them for their fatality risks.

We also recommend that, subject to a benefit-cost test, OSHA take a more aggressive stance and promulgate regulations mandating that employers provide safety and training materials in a language that their workers can understand. Currently, OSHA has dozens of regulations designed to convey job risks to workers through safety data sheets, training manuals, and labels across all major industries. Many of these regulations, however, do not require this training to occur in any language other than English. ${ }^{15}$ Because these training materials potentially serve as a mechanism for informing immigrant workers, we recommend that OSHA mandate that employers translate safety materials into an immigrant worker's native language. Because there are multiple training and risk communication efforts that are possible, where these vary in their stringency and their cost, we recommend that OSHA adopt the approach that has the greatest net benefits to society, i.e., benefits less costs. In recognition that most immigrant workers in dangerous occupations speak Spanish, we recommend that OSHA initiate pilot programs with requirements that training materials be translated into Spanish, since these regulations will likely pass a costbenefit test. Next, we suggest that OSHA investigate the costs and benefits of expanding language requirements to include translations into languages beyond English and Spanish. For occupations that employ many immigrants that do not speak Spanish or English, it may be socially optimal for OSHA to require safety materials to be translated into a language that that particular group of immigrants understands. In safety-training situations in which training is communicated verbally to workers, OSHA should require that safety procedures be communicated in a language that the workers can read or speak.

15 See infra Section VI.A. 


\section{BACKGROUND}

Before deriving the empirical results reached in this Article, this Part offers a broad summary of the demographic characteristics of immigrants in the United States along with an overview of the types of occupations that employ immigrants. Section A provides an overview of the average demographic characteristics of immigrants in the United States and Section B describes the types of jobs in which immigrants work.

\section{A. Broad Summary of Immigrant Characteristics}

This Section provides a broad overview of demographic characteristics of the immigrant population in the United States in order to contextualize this Article's findings with the immigrant population, generally.

In 2017, more than 44.5 million immigrants resided in the United States. ${ }^{16}$ Since the year 2000, immigrants have composed between 11 and 14 percent of the population of the United States. ${ }^{17}$ Furthermore, immigration is on the rise. After a low in the 1970s, immigration has again approached historical levels, and the immigrant share of the population has reached highs not seen since before World War I.18 Immigrants also composed about 17 percent of the labor force in 2019.19

Education attainment among immigrants is similar to that of United States natives. In 2016, approximately 32 percent of immigrants age twenty-five or older had a bachelor's degree or higher relative to 34 percent of U.S.-born adults. ${ }^{20}$ At the opposite end of the spectrum, immigrants were much more likely than U.S.-born adults to have less than a ninth-grade education. Over 16 percent of immigrants had less than a ninth-grade education, compared with 1.9 percent of the nativeborn population. ${ }^{21}$ The median age for the immigrant population in 2018 was greater than that of the U.S.-born population, with a median

16 U.S. Immigrant Population and Share over Time, 1850-Present, Migration Policy INST., https://www.migrationpolicy.org/programs/data-hub/charts/immigrantpopulation-over-time (last visited Jan. 13, 2020).

17 Id.

18 Id.

19 Press Release, U.S. Bureau of Lab. Stat., Foreign-Born Workers: Labor Force Characteristics-2019 (May 15, 2020), https://www.bls.gov/news.release/pdf/ forbrn.pdf.

20 Christine Gambino, Random Samplings: Immigrant Families and Educational Attainment, U.S. CEnsus BuREAU (Mar. 20, 2017), https://www.census.gov/ newsroom/blogs/random-samplings/2017/03/immigrant_familiesa.html.

21 Id. 
age of 45.2 years for immigrants compared to 36.3 years for natives. ${ }^{22}$ Women comprised about 52 percent of the immigrant population in $2018^{23}$ compared with about 51.1 percent of the native-born population. ${ }^{24}$ Unsurprisingly, immigrant populations are frequently of limited English proficiency; approximately 47 percent of immigrants over age five were of limited English proficiency. ${ }^{25}$

Turning next to national origin, Mexican immigrants compose the largest group of immigrants in the United States by a large margin. Approximately one in four immigrants in the United States are from Mexico. ${ }^{26}$ For comparison, Indians and Chinese were among the next two largest immigrant groups, comprising approximately 6 and 5 percent of the immigrant population, respectively. ${ }^{27}$ Forty-four percent of U.S. immigrants reported having Hispanic or Latino origins. ${ }^{28}$

It is worthwhile to briefly narrow in on Mexican immigrants, since they bear a significant portion of workplace fatalities. ${ }^{29}$ Note that these statistics are for all Mexican immigrants regardless of documentation status. Mexican immigrants ages twenty-five and older have much lower educational attainment than either the native-born population or other non-Mexican immigrant populations. ${ }^{30}$ In 2019, roughly 53 percent of Mexican immigrants lacked a high school diploma, compared to 26 percent of non-Mexican immigrants and 8 percent of the U.S.-born population. ${ }^{31}$ Fewer than 8 percent of Mexican immigrants had a bachelor's degree or higher. ${ }^{32}$ Overall, immigrants from Mexico are slightly younger than all immigrants but older than the U.S.-born

22 Jeanne Batalova et al., Frequently Requested Statistics on Immigrants and Immigration in the United States, Migration Policy Inst. (Feb. 14, 2020), https://www.migrationpolicy.org/article/frequently-requested-statistics-immigrantsand-immigration-united-states.

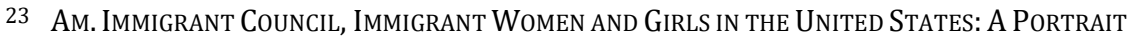
OF DEMOGRAPHIC DivERSITY (2020), https://www.americanimmigrationcouncil.org/sites/ default/files/research/immigrant_women_in_the_united_states.pdf.

24 Kaiser Family Foundation, Population Distribution by Sex, https://www.kff.org/ other/state-indicator/distribution-by-sex/?currentTimeframe $=0 \&$ sortModel $=\% 7 \mathrm{~B} \%$ 22colId\%22:\%22 Location\%22,\%22 sort\%22:\%22asc\%22\%7D (last visited February 9, 2020).

25 Emma Israel \& Jeanne Batalova, Mexican Immigrants in the United States, Migration Policy InST. (Nov. 5, 2020), https://www.migrationpolicy.org/article/ mexican-immigrants-united-states\#AgeEducationEmployment.

26 Id.

27 Id.

28 Id.

29 See generally Hersch \& Viscusi, supra note 5.

30 Israel \& Batalova, supra note 25.

31 Id.

32 Id. 
population. ${ }^{33}$ Finally, the Mexican immigrant population is less likely to be proficient in English than the overall foreign-born population. ${ }^{34}$ Sixty-six percent of Mexican immigrants reported limited English proficiency in 2019 relative to 46 percent of all immigrants. ${ }^{35}$

\section{B. Immigrant Distribution in the Labor Force}

Because this Article focuses on immigrants in the workplace, this Section provides a broad overview of where immigrants work in the American economy. In 2019, there were over twenty-eight million foreign-born workers in the U.S. labor force, about 17 percent of the total labor force. ${ }^{36}$ Moreover, immigrants disproportionately work in some of America's most dangerous jobs. According to the most recent 2019 statistics from the Bureau of Labor Statistics, 1.7 percent of immigrants work in farming, fishing, and forestry occupations compared to just 0.5 percent of the native population. ${ }^{37}$ In particular, immigrant workers dominated the construction occupation. Nearly 10 percent of the immigrant population work in construction while only 4.5 percent of the native population work in this occupation. ${ }^{38}$ The construction occupation is among the most dangerous in the country, with a fatality rate of 12.9 deaths per 100,000 workers. ${ }^{39}$

In contrast, immigrants are also disproportionately less likely to work in safer occupations. Though 18 percent of native-born workers are employed in the management occupations, only 13.1 percent of immigrants work in these types of jobs. ${ }^{40}$ Similarly, the professional occupations-such as computer engineering, education, and lawemploy fewer immigrants than native workers. Overall, 20.8 percent of immigrants were employed in these occupations compared to 24.2 percent of natives. ${ }^{41}$ Importantly, these occupations are among the safest. The fatality rate for the management occupations is 1.5 deaths

33 Id. (Mexican immigrants were forty-five years old on average, compared to fortysix years for all immigrants and thirty-seven years for U.S.-born population).

34 Id.

35 Id.

36 U.S. Bureau of Lab. Stat., supra note 19.

37 Id.

38 Id.

39 U.S. Bureau of Lab. Stat., Census of Fatal Occupational Injuries (CFOI)--Current, https://www.bls.gov/iif/oshcfoi1.htm\#rates (last visited Jan. 13, 2021) (available as a downloadable spreadsheet titled Hours-based fatal injury rates by industry, occupation, and selected demographic characteristics, 2019, Census of Fatal Occupation Injuries-Current and Revised Data).

40 U.S. Bureau of Lab. Stat., supra note 19.

41 Id. 
per 100,000 workers, while the fatality rate for the professional occupations is 0.7 deaths. ${ }^{42}$

The economics and policy literatures also find that immigrants, particularly Hispanic immigrants, work in the most dangerous occupations. Among the first to study this issue, Richardson, Ruser, and Saurez (2003) ${ }^{43}$ and Loh and Richardson (2004) ${ }^{44}$ both found that Hispanic workers have a higher fatality risk than the average worker. Orrenius and Zavodny (2009) found that immigrants, compared to native U.S. workers, work in riskier jobs. ${ }^{45}$ In a methodology akin to that used in this Article, Hersch and Viscusi (2010) showed that immigrants overall have a higher fatality rate than native U.S. workers and that this difference is driven by Mexican immigrants. ${ }^{46}$ They also showed that non-Mexican immigrants face a lower fatality rate than native U.S. workers. ${ }^{47}$ Finally, the most recent work in this area is a study published in the Monthly Labor Review by Byler (2013), which found that Hispanic/Latino workers have a higher overall occupational fatality rate than that of all workers and that foreign-born Hispanic/Latino workers experience higher injury rates than native-born Hispanic/Latino workers in certain occupations, such as sales or protective services. ${ }^{48}$

Overall, immigrants compose a disproportionate share of the dangerous occupations than U.S.-born workers. Many OSHA policiesincluding those dedicated toward helping immigrants ${ }^{49}$-are designed to improve safety in these dangerous industries. Accordingly, the remainder of this Article will address how immigrants fare in the workplace, with particular attention given to the traditional blue-collar occupations that have the highest fatality rates. ${ }^{50}$

42 U.S. BuREAU OF LAB. STAT., supra note 39.

43 Richardson et al. supra note 7, at 43.

44 Loh \& Richardson, supra note 7, at 42.

45 Orrenius \& Zavodny, supra note 7, at 535.

46 Hersch \& Viscusi, supra note 5, at 758.

47 Id.

48 Byler, supra note 7 , at 14.

49 See infra Section VI.A; see also supra note 10 and surrounding text.

50 The nine occupations that we designate as blue-collar occupations are: (i) healthcare practitioner and technical occupations, and healthcare support occupations; (ii) protective service occupations; (iii) food preparation and serving related occupations; (iv) building and grounds cleaning and maintenance occupations; (v) personal care and service occupations; (vi) farming, fishery, and forestry, and construction and extraction occupations; (vii) installation, maintenance, and repair occupations; (viii) production occupations; and (ix) transportation and material moving occupations. 


\section{COMPARING RISK LEVELS FOR IMMIGRANTS AND NATIVE WORKERS}

Previous research indicates that immigrants work in riskier jobs than U.S.-born workers, as measured by the average workplace fatality rates for these two groups. This Part updates that research using the newest data available from the Bureau of Labor Statistics and shows that immigrants still have an average workplace fatality rate higher than native workers. In addition, this Part also shows that immigrants remain locked into high-risk jobs over time using data from the NIS, a panel dataset that collected demographic, job, and other information on 8,573 new immigrants in 2003 and 2007. This Article is the first to use the NIS to assess how immigrants are progressing over time with respect to the riskiness of their employment. Section A of this Part describes our methodology for constructing fatality rates for three different risk measures. Section B uses these fatality rates to compare immigrant and U.S.-born risk levels. Finally, Section C shows that a substantial portion of immigrants in the NIS remained in high-risk jobs between 2003 and 2007.

\section{A. Construction of Fatality Rates}

This Section explains our methodology for constructing the fatality rates used in Sections III.B, III.C, and V.D of this Article. We follow the latest methodology used in the economics literature, which is also consistent with the general procedure used by the U.S. Bureau of Labor Statistics, to create hours-based fatality rates. ${ }^{51} \mathrm{~A}$ fatality rate measures the number of deaths per 100,000 workers. For instance, a fatality rate of 4.0 would mean that four workers died for every 100,000 workers.

The source of our fatality information is the Bureau of Labor Statistics' CFOI. The CFOI is a comprehensive census of all job-related fatalities in which each fatality is verified with multiple sources, including a worker's death certificate and worker's compensation record. ${ }^{52}$ The CFOI captures every fatality in the workplace and is widely accepted as the best data source for worker fatalities. ${ }^{53}$ In addition to information on the worker's age, industry, and occupation,

51 Elissa Philip Gentry \& W. Kip Viscusi, The Fatality and Morbidity Components of the Value of Statistical Life, 46 J. HEalth Econ. 90, 92 (2016) [hereinafter Gentry and Viscusi (2016)]; see also W. Kip Viscusi, Using Data from the Census of Fatal Occupational Injuries to Estimate the "Value of a Statistical Life", Monthly LaB. REV., Oct. 2013, at 1, 2; Elissa Philip Gentry \& W. Kip Viscusi, The Value of a Statistical Life for Transportation Regulations: A Test of the Benefits Transfer Methodology, 51 J. RisK \& UnCERTAINTY 53 (2015).

52 Gentry \& Viscusi (2016), supra note 51, at 92.

53 Id.; Viscusi, supra note 51, at 2. 
the CFOI data includes information on the worker's country of origin, which we leverage to construct fatality rates specific to immigrants.

We construct three different fatality rate measures based on three different units of analysis. These three measures are fatality rates indexed by industry, industry-immigrant status, and industryoccupation. To illustrate what a fatality rate for a given index means, consider the construction of fatality rates by industry. A fatality rate of 1.2 for the publishing industry would mean that there were 1.2 deaths per 100,000 workers in the publishing industry. We construct fifty such industries based on the Census codes and define industries using the same procedure as Gentry and Viscusi (2016). ${ }^{54}$

To explain how we construct fatality rates, consider the procedure used to create fatality rates indexed by industry. Constructing fatality rates first requires determining the value of the numerator-that is, we must determine the number of deaths in each industry for each year. To do so, we sum the total number of fatalities in each industry for workers between ages 16 and 64. This summed value is the numerator in the fatality rate.

Next, we must calculate the denominator. For this calculation, we follow the accepted hours-based fatality rate procedure and calculate the number of worker-hours in each industry cell using data from the National Bureau of Economic Research's Merged Outgoing Rotation Groups from the CPS. ${ }^{55}$ The CPS is published by the U.S. Census Bureau and is widely used in the labor economics literature as an accurate measure of the workforce. ${ }^{56}$ To calculate the number of hours, we multiply the average reported hours worked by employees in each industry by the number of employed workers in that industry. This value is the denominator for the fatality rate for a given year.

As a final note, because few deaths occur in some industries or occupations, we use three-year rolling averages to calculate the fatality rate. Thus, the numerator is the sum of fatalities for three years and the denominator is the sum of total hours worked by all employees each year for three years.

Formally, the annual fatality rate is

$$
\text { Fatality Rate }=\left(\frac{N}{E H}\right) * 200,000,000
$$

54 Gentry \& Viscusi (2016), supra note 51, at 92. For clarity, we matched the NAICS codes in the CFOI to census codes before aggregating the census codes into 50 industries according to CPS categories.

55 See id.

56 See, e.g., Gentry and Viscusi (2016), supra note 51. 
where $N$ is the number of fatal work injuries, $E H$ is the total hours worked by all employees during the calendar year, and 200,000,000 is the base for 100,000 full-time employees working a forty-hour workweek fifty weeks each year.

We also construct fatality rates indexed by industry-occupation and industry-immigrant status in the same way. ${ }^{57}$ For the industryoccupation fatality rates, we divide the sample into an industryoccupation grid, where the occupations are the nine blue-collar occupations that are widely accepted as some of the most dangerous in the country, and the fifty industries are the same as those used above. 58 Thus, a fatality rate indexed by industry-occupation refers to the fatality rate for a particular industry-occupation combination. For instance, a fatality rate of 1.0 for the publishing industry-transportation occupation cell would mean that one person working in the transportation occupation in the publishing industry died for every 100,000 workers in that job. Likewise, the fatality rate indexed by industry-immigrant status reflects the number of deaths per 100,000 workers in each industry based on immigrant status. We determine whether a fatality in the CFOI dataset belonged to an immigrant if the worker was born in a foreign region.

\section{B. Comparing Immigrant and Native Risk Levels}

This Section uses the fatality rates constructed in Section A to compare immigrant and native risks. We show that immigrants work a disproportionate share of fatalities and have a higher average fatality rate than native workers.

\section{Ratio of Immigrant Fatalities to Share of the Workforce}

Immigrants bear a disproportionate share of fatal workplace injuries, as evidenced by the fact that the ratio between their share of workplace fatalities is greater than their corresponding share of the workforce. Figure 1 plots the share of workplace fatalities belonging to immigrants against the share of immigrants in the workforce between 2003 and 2015.59 Between 2003 and 2015, immigrants composed between 11 and 14 percent of the workforce. ${ }^{60}$ During this time,

57 For a more detailed discussion of constructing fatality rates based on industryoccupation groupings, see Gentry \& Viscusi (2016), supra note 51, at 92.

58 See supra note 50.

59 To calculate the share of workplace fatalities belonging to immigrants, we divided the number of immigrant fatalities by the total number of fatalities in the CFOI data for each year.

60 We use data from the CPS to estimate the immigrant share of the workforce. 
however, they experienced between 15 and 18 percent of workplace fatalities. Accordingly, the relative immigrant share of fatalities exceeded 1.0 for each year illustrated in Figure 1. Though this ratio peaked in 2005 at 1.42, it has generally declined since, except for a recent bump from 1.06 to 1.16 in 2015, which reversed the downward trend of the previous two years. Nevertheless, compared to the starting points in 2003, the curves in Figure 1 have narrowed, as the relative share of immigrant fatalities more closely tracks their share in the workforce.

Overall, the fact that immigrants bear a disproportionate share of workplace fatalities provides evidence that they generally do worse than native workers, at least in terms of job risks. Moreover, this trend has persisted over time; at no time between 2003 and 2015 was the ratio between the immigrant share of the workforce and their share of fatalities less than 1.0.

Figure 1: Immigrant Share of Fatalities Plotted against Immigrant Share of the Workforce 61

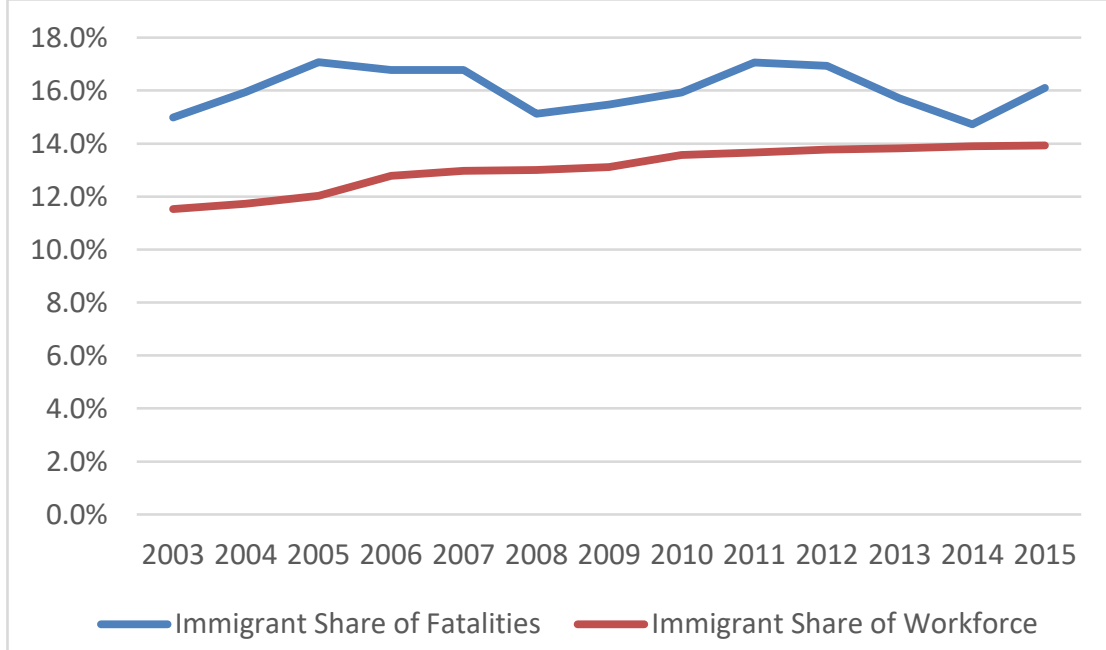

61 The totals and calculations of fatal injury data were generated by researchers at Vanderbilt University with restricted access to the CFOI research file. U.S. Bureau of Labor Statistics, Census of Fatal Occupational Injuries (restricted research file) (on file with author). 


\section{Comparing Immigrant and Native Fatality Rates}

Evidence based on risk levels associated with the workers in the CPS also shows that immigrants are concentrated in more dangerous jobs than native workers. The CPS is a large sample dataset that includes employment and demographic information for the native U.S. workforce along with information on a worker's country of origin, which is used to determine whether the worker is an immigrant. We describe the CPS data in more detail in Section V.A, infra, but for now it is sufficient to state that CPS includes information on a worker's industry, occupation, and immigrant status.

Table 1 presents descriptive statistics for three different fatality rate measures-industry, industry-occupation, and industryimmigrant-for CPS data from 2003, 2007, and 2015. The data are presented for different groups based on immigrant status and, if the worker is an immigrant, whether the worker emigrated from Mexico. We break out immigrants from Mexico separately because of related research showing that they bear the brunt of immigrant fatalities. ${ }^{62}$ Table 1 shows that fatality rates for all workers were relatively constant between 2003 and 2007, ranging from 4.4 deaths to 6.0 deaths per 100,000 workers in 2003 and 4.4 to 6.1 deaths per 100,000 workers in 2007. In 2015, however, the fatality rate for all workers decreased to between 3.3 and 5.2 deaths, depending on the measure, resulting in a decrease between 15 and 45 percent from 2007 to 2015. Immigrants experienced a similar trend. Their fatality rate across the three measures was approximately the same in 2003 and 2007, but the immigrant fatality rate was between 15 and 32 percent lower from 2007 to 2015. Much of this downward trend for both groups is due to the change in the industry mix of jobs in the economy.

In addition, by most fatality measures, immigrants experienced a higher average fatality risk than native workers in 2003, 2007, and 2015. To illustrate, consider 2007, where immigrants had a higher fatality rate than native workers using the industry and industryimmigrant fatality rate measures. This was also true in 2003, and in 2015 immigrants had a higher overall fatality rate than native workers across all three measures of job risks. Additionally, across all three years, Mexican immigrants had a substantially higher fatality rate than non-Mexican immigrants. For instance, in 2015, Mexican immigrants' fatality rate ranged from between 60 to 65 percent higher than nonMexican immigrants. Overall, immigrants from Mexico had the highest average fatality risk of any group assessed in the CPS.

62 Hersch \& Viscusi, supra note 5, at 768. 
Table 1: Risk Levels for Current Population Survey Sample Groups (rates per 100,000 full-time equivalent workers)63

\begin{tabular}{|c|c|c|c|c|c|}
\hline \multicolumn{6}{|c|}{2003} \\
\hline & $\begin{array}{l}\text { All } \\
\text { Workers }\end{array}$ & $\begin{array}{l}\text { Native } \\
\text { Workers }\end{array}$ & Immigrants & $\begin{array}{l}\text { Mexican } \\
\text { Immigrants }\end{array}$ & $\begin{array}{l}\text { Non- } \\
\text { Mexican } \\
\text { Immigrants } \\
\end{array}$ \\
\hline $\begin{array}{l}\text { Industry- } \\
\text { Occupation } \\
\text { Rate }\end{array}$ & 6.0 & 6.0 & 5.8 & 7.4 & 4.7 \\
\hline $\begin{array}{l}\text { Industry Rate } \\
\text { Industry- } \\
\text { Immigrant } \\
\text { Rate }\end{array}$ & 4.4 & 4.4 & 4.5 & 5.9 & 3.6 \\
\hline Sample Size & 67,857 & 56,444 & 11,413 & 4,660 & 6,753 \\
\hline \multicolumn{6}{|c|}{2007} \\
\hline & $\begin{array}{l}\text { All } \\
\text { Workers }\end{array}$ & $\begin{array}{l}\text { Native } \\
\text { Workers }\end{array}$ & Immigrants & $\begin{array}{l}\text { Mexican } \\
\text { Immigrants }\end{array}$ & $\begin{array}{l}\text { Non- } \\
\text { Mexican } \\
\text { Immigrants }\end{array}$ \\
\hline $\begin{array}{l}\text { Industry- } \\
\text { Occupation } \\
\text { Rate }\end{array}$ & 6.1 & 6.1 & 6.0 & 7.5 & 4.9 \\
\hline $\begin{array}{l}\text { Industry Rate } \\
\text { Industry- } \\
\text { Immigrant }\end{array}$ & 4.4 & 4.3 & 4.7 & 5.9 & 3.7 \\
\hline $\begin{array}{l}\text { Rate } \\
\text { Sample Size }\end{array}$ & $\begin{array}{l}4.8 \\
66,872\end{array}$ & $\begin{array}{l}4.7 \\
54,200\end{array}$ & $\begin{array}{l}5.1 \\
12,672\end{array}$ & $\begin{array}{l}6.5 \\
5,392\end{array}$ & $\begin{array}{l}4.1 \\
7,280\end{array}$ \\
\hline \multicolumn{6}{|c|}{2015} \\
\hline & $\begin{array}{l}\text { All } \\
\text { Workers }\end{array}$ & $\begin{array}{l}\text { Native } \\
\text { Workers }\end{array}$ & Immigrants & $\begin{array}{l}\text { Mexican } \\
\text { Immigrants }\end{array}$ & $\begin{array}{l}\text { Non- } \\
\text { Mexican } \\
\text { Immigrants }\end{array}$ \\
\hline $\begin{array}{l}\text { Industry- } \\
\text { Occupation } \\
\text { Rate }\end{array}$ & 5.2 & 5.2 & 5.4 & 7 & 4.4 \\
\hline $\begin{array}{l}\text { Industry Rate } \\
\text { Industry- } \\
\text { Immigrant }\end{array}$ & 3.5 & 3.4 & 3.9 & 5.1 & 3.1 \\
\hline Rate & 3.3 & 3.2 & 3.5 & 4.6 & 2.8 \\
\hline Sample Size & 60,800 & 49,315 & 11,485 & 4,579 & 6,906 \\
\hline
\end{tabular}

63 The totals and calculations of fatal injury data were generated by researchers at Vanderbilt University with restricted access to the CFOI research file. U.S. Bureau of Labor Statistics, supra note 61. 


\section{Immigrants Remain in High-Risk Jobs over Time}

Our concern with the well-being of immigrant workers would be dampened a bit if they were able to move out of high-risk jobs into safer pursuits. But this hopeful scenario is not the case. In addition to experiencing a higher fatality rate, immigrants also remain locked into high-risk jobs over time. This Section uses the NIS to empirically demonstrate that a large portion of new immigrants to the United States remained in high-risk jobs between the two waves of the NIS. Most strikingly, this pattern holds true for immigrants in the highest quartile of job risks-roughly half of all immigrants in this quartile of very risky jobs either increase their job risk or remain in a job with roughly the same risk level between the two waves. These results also have implications for OSHA policy, which we briefly discuss at the end of this Section.

To conduct our analysis in this Section, we use data from the NIS, which is a data source provided by the National Institutes of Health, National Institute of Child Health and Human Development, and the National Institute on Aging/Office of Behavioral and Social Science Research. The NIS sample consists of 8,573 new legal immigrants that received permanent resident status in 2003. The NIS is a panel dataset that tracks the same immigrant group across two survey waves. The first wave occurred in 2003, and the second was conducted between 2007 and 2009. Panel datasets observe the same individual over multiple periods ${ }^{64}$ and can therefore be used to explore what happens to the same person over time. The NIS collected information on legal immigrants on a variety of measures, such as the respondent's country of origin, English reading and writing proficiency, education attainment, employment history in the United States and their country of origin, gender, and income. Notably for this Section's purposes, the NIS also asks immigrants which occupation and industry grouping they belong to in both waves of the survey. This information, combined with fatality risks for every industry and occupation combination developed in the procedure outlined in Section III.B, permits us to analyze how many immigrants move from safer jobs to riskier ones, from riskier jobs to safer ones, or remain in the same job or risk level.

Before turning to our main results for this Section reported in Figure 2, we first provide summary statistics for the immigrants that compose the sample of immigrants for which complete industry and occupation data is available for both waves. This sample consists of 2,176 observations. Except for hourly wages and education, Table 2

\footnotetext{
64 Fumio Hayashi, Econometrics 323 (2000).
} 
provides summary statistics for every observation used to construct Figure 2. The average hourly wage in Wave 1 was $\$ 15.68$ per hour, which increased to $\$ 21.45$ in Wave 2. Since most of the immigrant characteristics summarized in Table 2 were relatively constant between the two periods, our discussion of this table will focus on the statistics in the second wave of the NIS. The average immigrant had fourteen years of education, ten years of work experience in the United States, and about 4.4 years of experience with their current employer. Approximately 60 percent of the sample is male, and 74 percent of the sample is married. Seven percent worked for the government and 12 percent belonged to a union. About 62 percent of the sample spoke English and 68 percent understood English. Finally, 37 percent were new arrivals to the United States.

Table 2: Summary Statistics for the NIS

\begin{tabular}{lllll}
\hline & Wave 1 & \multicolumn{3}{c}{ Wave 2 } \\
\cline { 2 - 5 } Variable & Mean & $\mathbf{N}$ & Mean & N \\
\hline Hourly Wage & 15.68 & 1,743 & 21.45 & 1,688 \\
Age & 36.86 & 2,176 & 40.64 & 2,176 \\
Education (Years) & 13.88 & 2,172 & 14.07 & 2,172 \\
Potential Experience in U.S. & 5.06 & 2,176 & 9.59 & 2,176 \\
Tenure & 2.68 & 2,176 & 4.37 & 2,176 \\
Male & 0.60 & 2,176 & 0.60 & 2,176 \\
Speak English & 0.62 & 2,176 & 0.62 & 2,176 \\
Understand English & 0.68 & 2,176 & 0.68 & 2,176 \\
Married & 0.71 & 2,176 & 0.74 & 2,176 \\
Government Employee & 0.05 & 2,176 & 0.07 & 2,176 \\
Union Member & 0.11 & 2,176 & 0.12 & 2,176 \\
New Arrival & 0.37 & 2,176 & 0.37 & 2,176 \\
\hline
\end{tabular}

Bearing this information in mind, we turn next to Figure 2, which provides a first-pass assessment of how immigrants moved among safe and risky jobs between the first wave of the NIS survey in 2003 and the second wave in 2007. Figure 2 graphs the percentage of workers that made a riskier job change, safer job change, or no job change. We define a job change as any change in a worker's industry or occupation category between 2003 and 2007. For this analysis, we include all occupations rather than only blue-collar occupations. ${ }^{65}$ As an

\footnotetext{
65 We impose this restriction later.
} 
illustrative example to understand how Figure 2 was created, suppose that a person worked as a machinist in a foundry in 2003. In Wave 1, this person would then be classified in the "Metals Manufacturing" industry and the "production" occupation. If in 2007 the worker remained at the foundry but became a construction laborer making new buildings for the foundry, he would remain in the same industry but move to a new occupation group, construction. Thus, he would be classified as a job mover for our purposes, and, in this instance, his workplace fatality risk would have increased, so he would be classified as a "riskier job changer." 66 We also break out Mexican immigrants separately in Figure 2 because previous research and the results reported in this Article indicate that Mexican immigrants face the highest overall fatality risks and receive the lowest monetary compensation for those risks. ${ }^{67}$

Figure 2 shows that immigrants are more likely to remain in their jobs or switch to riskier jobs than they are to move to safer jobs. Looking first at Mexican immigrants, who composed about 267 of the 2,171 immigrants for which complete data was available, 38 percent moved to a riskier job, 27 percent stayed in the same job, and 35 percent moved to a safer job. Thus, 65 percent of Mexican immigrants in the sample made a riskier change or failed to improve their job risk. To be sure, some of the "stayers" were already in safe jobs, but the fact that more Mexican immigrants moved to a more dangerous job than moved to a safer job shows that a large portion of Mexican immigrants did not get safer over time. Figure 2 also shows that Mexican immigrants are the only group who failed to improve their overall level of safety because more workers moved to riskier jobs over time than moved into safer employment.

Figure 2 also shows that many non-Mexican immigrants did not transition to safer jobs. Though 36 percent of non-Mexican immigrants made a safer job change, the remaining 64 percent of non-Mexican immigrants remained in their same job or made a riskier job change. Finally, looking at all immigrants, Figure 2 shows that 36 percent of all immigrants moved to a safer job, 32 percent found a riskier job, and 32 percent remained in the same job. Thus, roughly two out of every three immigrants stayed in the same risk group or increased their risk when

66 This worker would also be classified as a job changer if the worker remained in the same machinist occupation in both waves, but moved industries to work for, say, a paper mill classified in the Wood Products Manufacturing industry. Whether this change would be classified as a safer or more dangerous change would depend on whether the risk of dying in the new job was greater or less than that relative to his old job.

67 Hersch \& Viscusi, supra note 5; Byler, supra note 7, at 14. 
they changed jobs. Again, it is likely that some of the "stayers" were already in safe jobs, but the fact that nearly one-third of immigrants moved to a riskier job is indicative of the fact that many immigrants failed to improve in terms of workplace safety.

Stepping back, Figure 2 illustrates overall that a substantial portion of immigrants did not sort themselves into safer jobs between 2003 and 2007. This, in conjunction with the fact that immigrants face higher job risks overall, ${ }^{68}$ suggests that immigrants enter jobs with high fatality risks when they first arrive, and then a substantial proportion, based on the results of Figure 2, fail to move into safer jobs as time progresses.

These results inform our understanding of the lack of immigrant progress under the Bush Administration. Although OSHA policies may have encouraged some immigrants to transfer into safer occupations over time, Figure 2 shows that a large portion of immigrants switched to a higher-risk job between 2003 and 2007.

Figure 2: Changes in Job Risk (Percentages) ${ }^{69}$

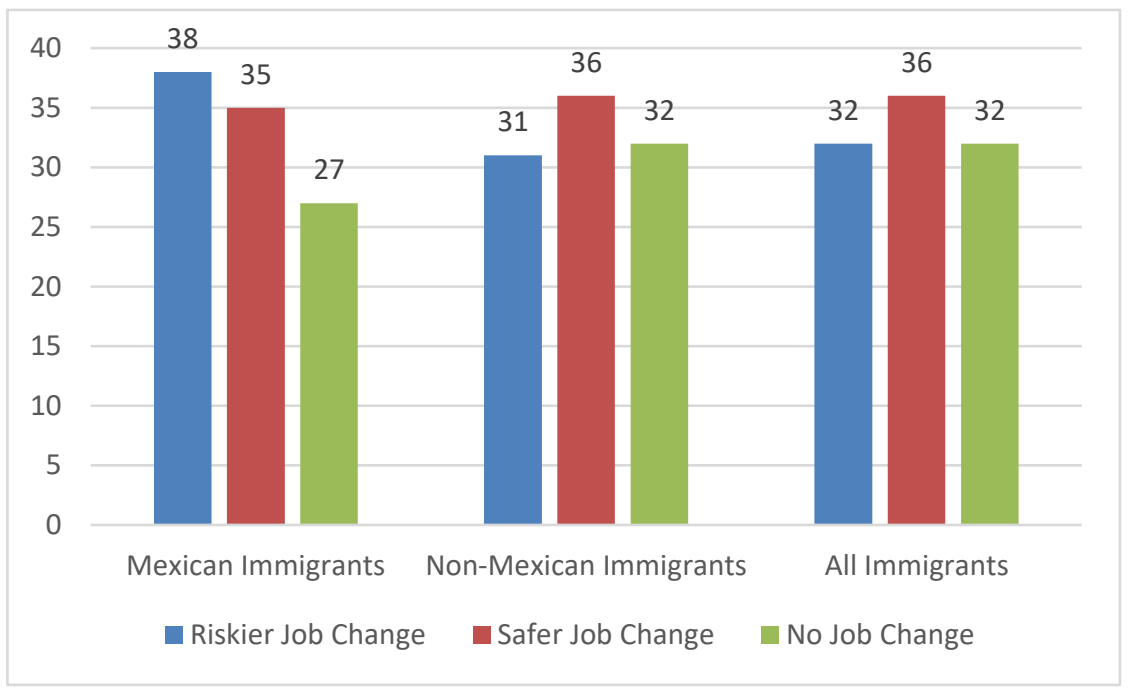

Another way to assess whether immigrants substantially sort into safer jobs is to explore how immigrants change job risks based on their Wave 1 risk quartile. We conduct this analysis in Figures 3, 4, and 5. To

\footnotetext{
68 See infra Section III.B.
}

69 The totals and calculations of fatal injury data were generated by researchers at Vanderbilt University with restricted access to the CFOI research file. U.S. Bureau of Labor Statistics, supra note 61. 
construct these figures, we divide immigrants into four different risk groups based on the fatality rate that they faced in their industryoccupation combination in the first wave of the NIS survey. The first quartile consists of immigrants in the lowest 25 percent of job risks, the second quartile consists of immigrants in the second-lowest 25 percent of job risks, and so on. We classify an immigrant as belonging to the "No Risk Change" group if the fatality rate for the immigrant's second job was within 10 percent of the fatality rate for the immigrant's first job in Wave 1 of the NIS. To illustrate, suppose a person's job had a fatality rate of 1.0 death per 100,000 workers in Wave 1 of the NIS. This person would belong to the second quartile in Wave $1 .^{70}$ If the fatality rate of their second job was 0.90 deaths per 100,000 workers, this person would be classified in the "No Risk Change." If, however, this person moved to a job that had a fatality rate of 0.89 deaths per 100,000 workers, they would belong to the "Risk Decreased" group. If their second job had a fatality rate of greater than 1.1 deaths per 100,000 workers, they would belong to the "Risk Increased" group.

Figures 3, 4, and 5 are useful because they permit analyzing whether immigrants remained in approximately the same risk group in both waves of the NIS survey or if they increased or decreased their risk between the two waves. In short, these figures provide a finer framework in which to analyze how immigrants fare in terms of job risks over time. If a large portion of immigrants is moving to a higherrisk quartile or remaining in the same risk quartile, we have evidence suggesting that immigrants are not sorting themselves into safer jobs over time. Figures 3, 4, and 5 are based on 2,158 total observations. ${ }^{71}$

70 The risk groups in the four quartiles in Figures 3, 4, and 5 are as follows: The first quartile includes all immigrants with workplace fatality risks between zero and 0.76 deaths per 100,000 workers. The second quartile includes all immigrants with workplace fatality risks between 0.76 and 1.14 deaths. The third quartile includes all immigrants with fatality risks between 1.15 and 2.81 deaths. Finally, the fourth quartile includes all immigrants with fatality risks between 2.82 and 35.88 deaths per 100,000.

71 The observations are lower because we lack some fatality rates for some industryoccupation groups due to the nature of the construction of fatality rates indexed by industry-occupation. Otherwise, the 2,158 observations that we have data for perfectly overlap with the 2,176 observations used to construct Figure 2. 
Figure 3: Risk Changes by Quartile, All Immigrants (Percentages) ${ }^{72}$

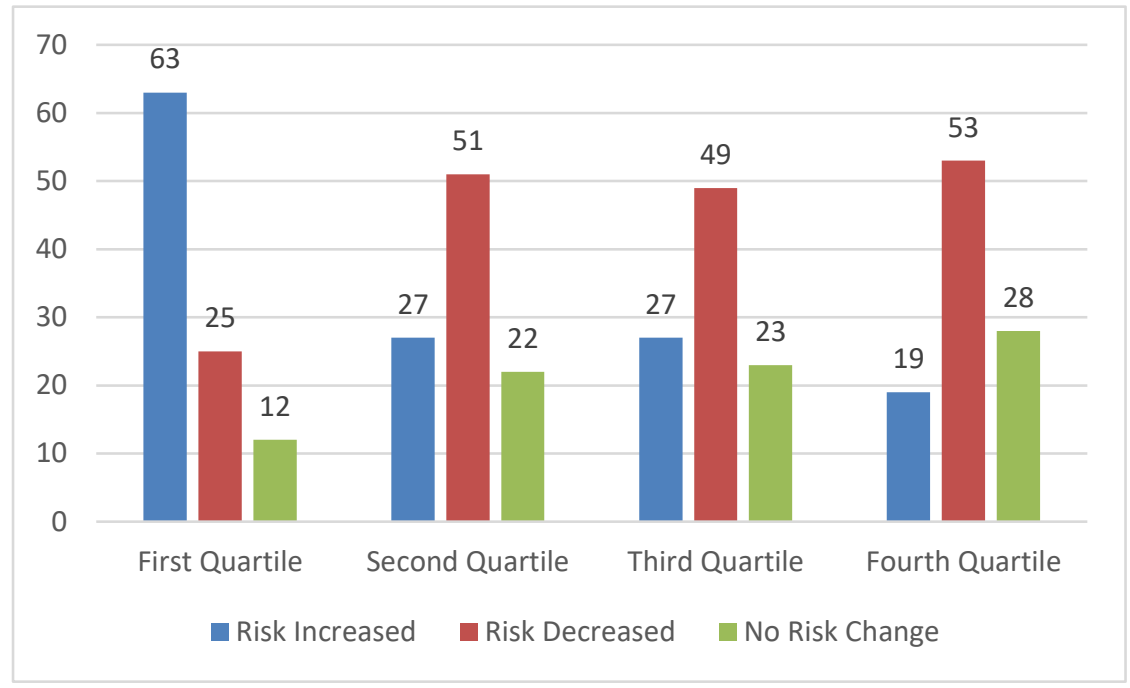

Figure 3 analyzes risk changes for all immigrants for which information was available. The first quartile of Figure 3 shows that 63 percent of immigrant workers moved to a job with a higher fatality risk in the second wave of the NIS survey. To be sure, those in the lowest risk group that switch jobs are hard pressed to find a job with a similar or lower fatality rate, but the fact that nearly two-thirds of workers in the first quartile increased their risk suggests some immigrants are not remaining in safe jobs over time. Indeed, this phenomenon is born out in the other three quartile groups as well. In each of the three groups, about 50 percent of immigrants decreased their risks, but the other 50 percent remained in the same risk group or moved to a job with a higher fatality risk between the first and second waves of the NIS. Notably, nearly one out of every two immigrants in the fourth quartile-which consists of those in the most dangerous jobs and is, therefore, most indicative of how immigrants are doing in terms of job safetyincreased their fatality risk or failed to move to a job with a lower fatality risk. Overall, Figure 3 illustrates that though there has certainly been

72 The totals and calculations of fatal injury data were generated by researchers at Vanderbilt University with restricted access to the CFOI research file. U.S. Bureau of Labor Statistics, supra note 61. The risk-quartiles in Figures 3, 4, and 5 are as follows: The first quartile consists of the safest industry-occupation groups with the lowest fatality rates. The second quartile includes the second safest industry-occupation groups. The third quartile includes the third safest industry-occupation groups. The fourth quartile includes the most dangerous industry-occupation groups with the highest fatality rates. 
some improvement in terms of immigrants sorting themselves into safer jobs, a substantial portion, especially those in the riskiest quartile, do not do so.

Figure 4: Risk Changes by Quartile, Mexican Immigrants (Percentages) ${ }^{73}$

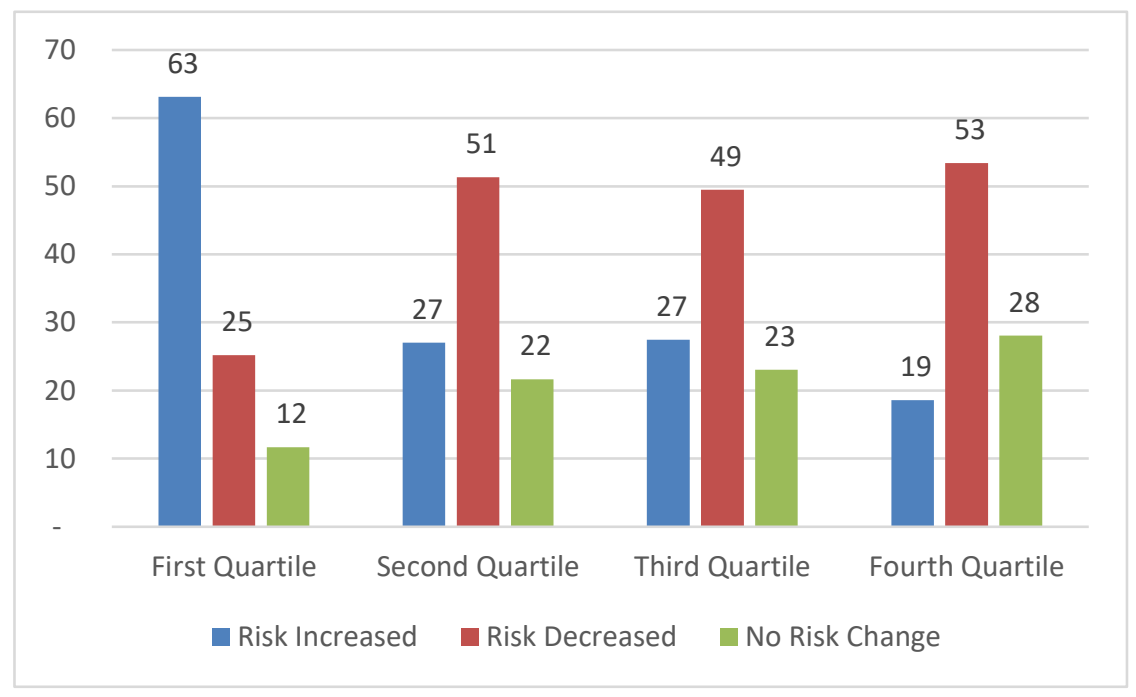

Figure 4 breaks out risk changes by quartile for Mexican immigrants, who represent 265 of the 2,158 immigrants for which complete data was available. Here, the first quartile largely mirrored what occurred in the first quartile of Figure 3: about two-thirds of Mexican immigrants increased their fatality risk in the second wave of the NIS, while the remainder stayed in a similar risk group or decreased their overall fatality risk. Likewise, the activity in the second and third quartiles in Figure 4 aligned with that of Figure 3. Again, the most telling quartile in terms of how immigrants are doing in the labor market is the fourth, high-risk quartile. Here, the movement between risk groups in the fourth quartile for Mexican immigrants mirrored the fourth quartile for all immigrants in Figure 3. Approximately half of all Mexican

73 The totals and calculations of fatal injury data were generated by researchers at Vanderbilt University with restricted access to the CFOI research file. U.S. Bureau of Labor Statistics, supra note 61. The risk-quartiles in Figures 3, 4, and 5 are as follows: The first quartile consists of the safest industry-occupation groups with the lowest fatality rates. The second quartile includes the second safest industry-occupation groups. The third quartile includes the third safest industry-occupation groups. The fourth quartile includes the most dangerous industry-occupation groups with the highest fatality rates. 
immigrants in this quartile increased their job risks or remained in the fourth riskiest quartile, while about half reduced their workplace fatality risks between the two waves.

Finally, Figure 5 analyzes risk changes for non-Mexican immigrants. Figure 5 largely mirrors the results illustrated in Figure 3. Again, the first quartile had the largest percentage of immigrant workers that moved to a higher-risk job. The job movement in the second, third, and fourth quartiles largely mirrored that exhibited for all immigrants in Figure 3. Notably, in the fourth and most dangerous risk quartile, just under half of all non-Mexican immigrants remained in the same risk group or increased their fatality risk.

Figure 5: Risk Changes by Quartile, Non-Mexican Immigrants

(Percentages) ${ }^{74}$

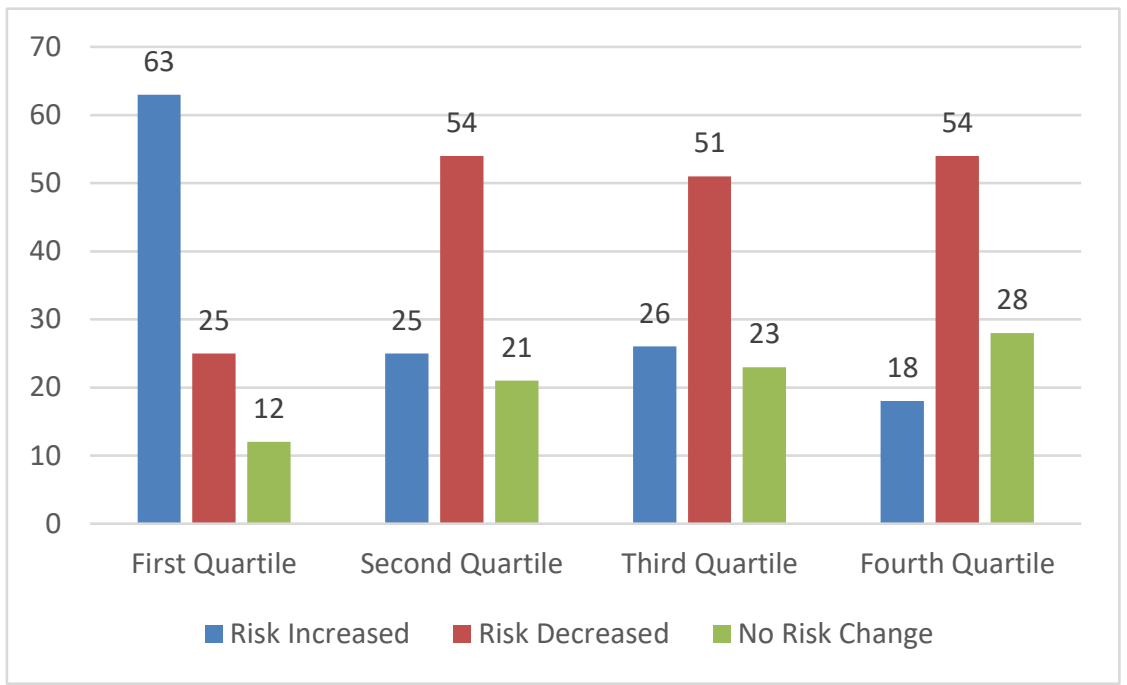

Overall, Figures 3 through 5 show that many immigrants did not substantially migrate into safer jobs between the first and second waves of the NIS. Certainly, many immigrants across all quartiles did move to a safer job. But the fourth quartile of Figures 3, 4, and 5-which

74 The totals and calculations of fatal injury data were generated by researchers at Vanderbilt University with restricted access to the CFOI research file. U.S. Bureau of Labor Statistics, supra note 61. The risk-quartiles in Figures 3, 4, and 5 are as follows: The first quartile consists of the safest industry-occupation groups with the lowest fatality rates. The second quartile includes the second safest industry-occupation groups. The third quartile includes the third safest industry-occupation groups. The fourth quartile includes the most dangerous industry-occupation groups with the highest fatality rates. 
represents the quartile with the most dangerous occupations-shows that a substantial portion of immigrants remained in high-risk jobs or increased their job risks. Thus, while some immigrants improved, many did not, and this fact-coupled with the results in Sections III.B and V.D, infra-shows that immigrants still face many struggles in the workplace: they experience higher average fatality rates, are not compensated for their job risks, and, in many cases, remain locked into high-risk jobs over time. The results developed in this Section also shed light on some of OSHA's policies under the Bush Administration. At this time, OSHA compiled several Spanish-language resources and created the Hispanic Workers Task Force to improve worker safety. ${ }^{75}$ Given that a large portion of the immigrant population remained in high-risk jobs or moved to high-risk jobs between 2003 and 2007, however, these trends suggest that the Bush Administration's efforts were not sufficient to enable immigrant workers to transition into safer occupations.

\section{DO IMMIGRANTS GET PAID FOR RISKY JOBS? THEORY OF THE VSL}

Part III of this Article demonstrated that immigrants experience a higher overall fatality rate than native workers and that a significant portion of immigrants remained in dangerous jobs over time. The results developed in Part III may be less concerning, however, if it is also the case that immigrant workers receive compensation in the form of higher wages, or hazard pay, for their increased job risks. Research in the economics literature suggests that immigrants do not receive wage compensation for their increased job risks, as reflected by the fact that their VSL is substantially lower than the VSL for native workers, and for some immigrant groups may even be zero. ${ }^{76}$ This Part discusses a theoretical explanation for why this may be the case. To preview, immigrants receive lower hazard pay because they face a different wage-offer curve than native workers, resulting in a lower compensating differential for immigrants along with a lower accompanying VSL. ${ }^{77}$ Section A provides background information to better understand the VSL. Section B describes the theoretical derivation of the VSL. Finally, Section C explains in more detail why the VSL may differ for immigrant workers.

75 These policies are described in more detail in Part VI.

76 Hersch \& Viscusi, supra note 5, at 750.

77 Id. 


\section{A. What is the VSL?}

The VSL quantifies the benefit of avoiding a fatality. Today, the VSL estimates range from 9 to 11 million dollars. ${ }^{78}$ This figure reflects the total compensation required per expected workplace death. To illustrate, suppose the average annual fatality rate for all workers is one death per 10,000 workers. ${ }^{79}$ Suppose also that in return for bearing this risk, workers receive an annual wage premium of $\$ 1,000.80$ The amount of compensation that this group of workers would receive for one workplace death would therefore be $\$ 10,000,000$ or $10,000 * \$ 1,000$. Accordingly, the VSL would equal $\$ 10,000,000$. In general, then, the VSL can serve as a measure of whether workers receive compensation for their job risks.

Though estimates of the VSL for workers generally are between 9 and 11 million dollars, the estimated VSL for immigrants is much lower. In 2010, the estimated VSL for immigrants using the industryoccupation fatality rate measure was $\$ 3.19$ million, which, at the time, compared to a VSL of $\$ 8.8$ million for native workers, indicates that immigrants receive less hazard pay than U.S.-born workers. ${ }^{81}$ Mexican immigrants fared particularly poorly as they received no net wage compensation for fatality risks, resulting in a VSL of zero for these workers. ${ }^{82}$ The following sections explain how immigrants can receive less compensation for job risks than native workers by first outlining the theoretical derivation of the VSL, followed by a theoretical rationale for why immigrants have a lower VSL than native workers.

\section{B. Theoretical Derivation of the VSL}

The Value of a Statistical Life is grounded in the fundamental assumption that labor markets involve the exchange of goods and services between workers and firms. ${ }^{83}$ More dangerous jobs are generally less desirable to risk-averse workers, and so, holding everything else equal, these workers require higher wages to work

78 W. Kip Viscusi, Pricing Lives: Guideposts for a SAFER Society 6 (2018).

79 Id.

80 Id. The $\$ 1,000$ figure is derived statistically and includes controls for workers and occupation characteristics.

81 Hersch \& Viscusi, supra note 5, at 763. Estimates of the VSL using a different dataset, the NIS, showed that immigrants had a VSL between $\$ 9$ and $\$ 13$ million. Mexican immigrants still had a negative VSL, however. Id. at 767

82 Id. at 767.

83 Thomas J. Kniesner \& W. Kip Viscusi, The Value of a Statistical Life, OxFord Rsch. ENCYCLOPEDIA OF ECON. AND FIN. (2019), https://doi.org/10.1093/acrefore/9780190625 979.013.138. 
those more dangerous jobs. ${ }^{84}$ In economic terms, this is referred to as a compensating differential. ${ }^{85}$ On the firm side, safer jobs are more costly for firms to provide, and, again holding everything else equal, firms will have to pay lower wages for safer jobs in a perfectly competitive environment, and some workers will accept the lower wages in return for safer jobs. ${ }^{86}$ This results in a locus of wage and job-risk combinations in which the quantity of labor demanded equals the quantity of labor supplied at every possible safety level. In economic terms, this is referred to as the labor market hedonic equilibrium.

The labor market hedonic equilibrium can be described algebraically by the equation $w=w(p)$, where $w$ represents the wage and $p$ represents the probability of a fatal injury at work. ${ }^{87}$ In other words, the wage is a function of the job risk. Furthermore, the more dangerous the job, the more firms must pay in wages, everything else the same, to attract workers to that job. Note also that the proper comparison is within an industry and occupation across workplaces. So even though lawyers have higher paid and safer jobs than construction workers, comparing lawyers to construction workers would be inapt. Rather, the focus is on situations such as test pilots being more highly paid than commercial airline pilots because test pilots face such a higher risk of death. 88

The graphical representation of the labor market hedonic equilibrium is a concave function, and the VSL directly follows from the numerical value of the slope of the labor market hedonic wage equilibria. ${ }^{89}$ To illustrate, consider an example similar to the one outlined in Section IV.A. Suppose the probability of an accidental death in the workplace is one death per 10,000 workers. Suppose also that the labor market reveals that for this level of risk the typical worker must be paid an extra $\$ 1,000$ per year to accept a job that has this risk level. As a group, then, 10,000 workers would need to collect $\$ 10$ million more to compensate them for the risk that one more of their number were to be killed in the next year. In this example, then, the VSL is $\$ 10$ million. ${ }^{90}$

84 Id.

85 Id.

86 Id.

87 Id.

88 Id. Another example is for janitors. Janitors who clean the inside of a nuclear reactor are paid about 16 times more than janitors who clean commercial office buildings. Id.

89 Kniesner \& Viscusi, supra note 83.

90 This is also the amount that the same group of workers would be willing to pay via wage reductions to have a safer job where one fewer worker in their group would be fatality injured. $I d$. 
More broadly, the VSL equals all the additional wage payments that employers must pay to compensate their workers for workplace fatality risk.

Another important result at play here involves the sorting of workers to jobs in various firms. Because of the nature of the labor market, firms with low workplace safety costs will hire those workers who are least willing to bear workplace risks. ${ }^{91}$ Similarly, firms with high safety costs will hire workers who are most willing to bear workplace risks that threaten their health or safety at work. ${ }^{92}$ In the most simplified theoretical version of the VSL, this sorting of workers to firms is economically efficient. This simplified version assumes, however, that all workers face a common labor market offer curve. ${ }^{93}$ In practice, it may be the case that workers face different offer curves. As explained in more detail in the following Section, this market segmentation explains why immigrants do not receive compensation for job risks. ${ }^{94}$

\section{The VSL for Immigrant Workers}

This Section explains why the VSL may differ for immigrant workers. This Article, along with previous research in economics, 95 shows that immigrants, especially those from Mexico, encounter large workplace fatality risks without receiving significant wage compensation in return. ${ }^{96}$

The explanation for why immigrants fare worse in the labor market is grounded in standard economic wage theory. To illustrate, begin with the same labor market described in Section IV.B. Now, however, relax the assumption that all workers face the same wage-offer curve and instead let there be two offer curves, one for native workers and one for immigrants. ${ }^{97}$ Economists refer to a labor market characterized by two offer curves as a segmented labor market. ${ }^{98}$ So, even though immigrant workers may be able to choose from among the same set of jobs as native workers, they receive a lower level of compensation for each level of risk. ${ }^{99}$ Furthermore, segmented labor markets are theoretically

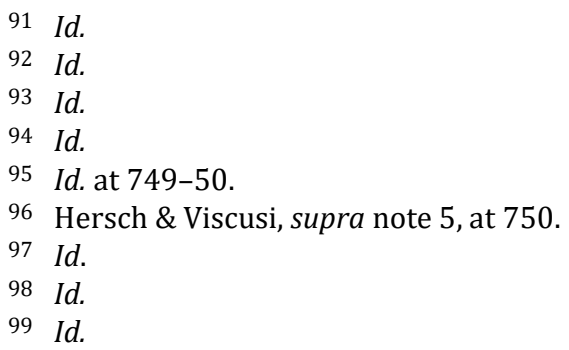


possible so long as employers can distinguish between the two labor market groups and offer different sets of jobs based upon observable characteristics of one group. ${ }^{100}$ Immigrants can be readily identified by their potential employers, therefore they could face a different provision of wage-offer curves based upon their status as immigrants. ${ }^{101}$

The next Part uses the theoretical insights developed here to design an empirical model that shows that immigrants fail to receive hazard pay for their workplace fatality risks.

\section{RESULTS}

This Section uses data from the CPS to show that immigrants do not receive a wage premium for their workplace fatality risks. We also show that this result holds for Mexican immigrants. To reach this result, we leverage the theoretical insights developed in the previous Part to design an empirical specification that accounts for a segregated labor market in which immigrants face a different wage-offer curve than native workers. Moreover, the results in this Part bolster the conclusion that immigrants suffer in the labor market relative to native workers. Section III.B showed that immigrants face a higher average fatality risk than native workers, Section III.C showed that a substantial portion of immigrants remains locked into high-risk jobs over time, and this Part empirically shows that immigrants do not receive hazard pay for job risks.

This Part proceeds as follows. Section A discusses the data used to derive these results. Section B outlines our empirical specification. Section $C$ discusses previous results in the economics literature showing that immigrants do not receive hazard pay for job risks. Finally, Section D provides new evidence that immigrants, even in 2015, do not receive compensation for workplace fatality risks.

\section{A. Data Sources}

This Section uses data from the CPS to estimate log-wage regression equations that test whether immigrants receive compensation for job risks. The CPS is a large sample dataset that includes employment and demographic information for the native U.S. workforce along with information on a worker's country of origin, which is used to determine whether the worker is an immigrant. ${ }^{102}$ We use the

\footnotetext{
100 Id. at 751.

101 Id. at 751.

102 National Bureau of Economic Research, Current Population Survey (CPS) Data at the NBER, https://www.nber.org/research/data/current-population-survey-cps-datanber (last visited February 9, 2021).
} 
Merged Outgoing Rotation Groups (MORG), a subsample of the CPS, in our analysis because this sample includes information on the worker's income. The MORG also includes information on worker age, education, gender, race, occupation, and industry. Summary statistics for the key variables of the log-wage regression equation used to estimate fatality risks are reported in Appendix Table 1. We focus on 2007 and 2015 because 2007 corresponds with the second year of the NIS survey and 2015 is the most recent year for which our CFOI data is available. To compare with the first wave of the NIS survey in 2003, we reference results from Hersch and Viscusi (2010), described in Section V.C. Overall, the results from these regressions can, in conjunction with results from the NIS survey, inform our understanding of how immigrants fare in the workplace.

We made a number of restrictions to the sample to align with best practices in the economics literature. First, we restricted the CPS sample to workers in occupations that were traditionally characterized as blue-collar jobs since the greatest job risks are associated with these occupations. ${ }^{103}$ This restriction is common throughout the VSL literature.104 We also limit the CPS samples to workers that are not selfemployed-since the CPS does not report earnings for self-employed workers-and to those with hourly wages from $\$ 1.50$ to $\$ 100$ and between the ages of eighteen and sixty-four. Summary statistics for the variables included in this analysis are presented in Appendix Table 1.

Appendix Table 1 shows that the average hourly wage in 2007 and 2015 was $\$ 16.60$ per hour and $\$ 19$ per hour, respectively. Experience ranged from 22 years in 2007 to 22.4 years in 2015. Time spent receiving education was relatively constant across the two sample years, ranging from 12.5 and 12.8 years. Union membership declined from 14.8 percent of the 2007 sample to 12.8 percent of the 2015 sample. The percent of white workers was roughly the same in 2007 and 2015, ranging between 79.1 percent and 81.9 percent of each sample. The percent of Hispanic workers increased between 2007 and 2015-approximately 17.5 percent of the sample in 2007 was Hispanic compared to 18.8 percent in 2015 . The percentage of immigrants was 18.9 percent in both 2007 and 2015. Finally, the percentage of Mexican immigrants was 8.1 percent in 2007 and 7.5 percent in 2015.

\footnotetext{
103 These occupations are listed above in footnote 58.

104 See, e.g., Gentry \& Viscusi (2016), supra note 51, at 92; Hersch \& Viscusi, supra note 5 , at 755 .
} 


\section{B. Empirical Specification}

The empirical specification applies the theoretical insights developed in Part IV. We leverage the canonical log-wage equation used throughout labor economics to test whether immigrants are compensated for their workplace risks similarly to native workers. ${ }^{105}$ In short, this equation represents the $\log$ (Hourly Wage) for a given worker as a linear function of all of the worker's individual characteristics, such as the worker's education or gender, along with the worker's particular job, the fatality rate for that job, and the worker's immigrant status. In this way, this regression specification permits us to estimate the effect of the worker's workplace fatality risk while controlling for other factors that affect the worker's wage, such as education, gender, or race. This regression specification also permits a separate labor market equilibrium for immigrants that would differ in terms of the wage level and slope of the estimated wage-risk combination, as outlined above. 106 We achieve this separate equilibrium by including an indicator variable for whether the worker is an immigrant as well as an interaction term for immigrant status and the worker's workplace fatality rate. ${ }^{107}$

The log-wage equation takes the following form:

$$
\begin{aligned}
\ln (\text { Wage })= & \beta_{0}+\beta_{1} X+\beta_{2} \text { Fatality Rate }+\beta_{3} \text { Immigrant }+ \\
& \beta_{4} \text { Immigrant } x \text { Fatality Rate }+\epsilon
\end{aligned}
$$

The dependent variable in this equation is the log of wages for an individual worker. The hourly wage is reported directly for most workers in the CPS, but we calculated the hourly wage for some workers by dividing weekly earnings by the worker's usual weekly hours (CPS). Control variables are reflected by the vector $X$. These variables include indicator variables for a worker's race (White, Black, American Indian, Asian or Pacific Islander, or more than one race reported), Hispanic ethnicity, sex, marital status, union status, indicator variables for the worker's broad occupation group, and indicators for whether the worker is employed by the government, employed full time, or paid on an hourly basis. We also control for a worker's education. In the CPS, we impute education using the highest education attainment of a worker. The CPS does not have specific information on work history.

105 See, e.g, Joseph E. Aldy \& W. Kip Viscusi, Adjusting the Value of a Statistical Life for Age and Cohort Effects, 9 REV. ECON. \& STAT. 573, 575 (2008); Hersch \& Viscusi, supra note 5 , at 753 .

106 Id.

107 Id. 
We therefore approximate experience by potential experience, which is defined as age minus years of education minus five. ${ }^{108}$

The key variables in this regression are the fatality rate, a binary variable for immigrant status, and an interaction term, Immigrant $x$ Fatality Rate. We use the industry fatality rate measure in our primary regression. Immigrant is a binary variable equal to one if the worker is an immigrant and zero otherwise. The final term, Immigrant $x$ Fatality Rate, represents the interaction between immigrant status and the fatality rate. Including this term is worthwhile for two reasons. First, as explained above, including the interaction term permits a separate labor market equilibrium for immigrant workers. Second, interaction terms in general permit a more nuanced understanding of how immigrant workers are compensated for their fatality risks. The interaction term lets us test whether the effect of the fatality rate on a worker's wages differs based on whether the worker is an immigrant.

\section{Results in the Previous Literature}

Before providing new estimates of immigrants' failure to receive hazard pay, we show in this Section that our results align with previous results in the literature, implying that Mexican immigrants, in particular, continue to fail to receive wage compensation for the high fatality risks that they face. Most notably, Hersch and Viscusi (2010) use the CPS and Wave 1 of the NIS to estimate log-wage equations similar to those used in this Article ${ }^{109}$ to test whether immigrant workers receive compensation for their workplace risks. Hersch and Viscusi found that immigrants are concentrated in high-risk jobs and receive little to no boost in wages to compensate them for their on-the-job risks. ${ }^{110}$ They also showed that Mexican immigrants suffer: despite incurring much higher fatality risks than U.S. workers, Mexican immigrants receive no compensation for job risks. ${ }^{111}$ Hersch and Viscusi also calculated VSLs for all workers, immigrant workers, and Mexican immigrant workers. Using the CPS dataset, Hersch and Viscusi found that the VSL for native workers ranges from $\$ 8.8$ million to $\$ 10.22$ million while the VSL for immigrant workers ranges from $-\$ 3.64$ million to $\$ 3.19$ million, depending on the fatality rate measure used in the analysis. ${ }^{112}$ Using the NIS dataset, which only includes immigrants, Hersch and Viscusi found

108 This is the standard practice in the literature. See, e.g., id. at 756.

109 See infra Section V.D.

110 Hersch \& Viscusi, supra note 5, at 749.

111 Id.

112 Id. at 763. 
that the VSL for immigrants ranged between $\$ 7.21$ and $\$ 9.35$ million. . $^{113}$ Immigrants from Mexico, however, receive no wage compensation for their job risks. In fact, Hersch and Viscusi found that the VSL for these immigrants was negative.

\section{New Estimates of Immigrant's Failure to Receive Hazard Pay}

This Section provides new estimates illustrating that immigrants, particularly those from Mexico, fail to receive hazard pay for workplace fatality risks. We first present results for immigrants generally before breaking our results into Mexican and non-Mexican immigrant groups.

Table 3 presents estimates of the key risk and immigrant status variables using the CPS dataset for 2007 and 2015. We focus on the results using the industry fatality rates for ease of analysis. Overall, Table 3 shows that all workers receive a statistically significant compensating differential for fatality risks. Immigrants, however, do not receive any compensation for the fatality risks they face on the job.

Table 3 shows that all workers receive positive compensation for job risks because the coefficient of the fatality rate variable is positive and statistically significant at the five percent level. We can therefore calculate the VSL for all workers in this specification. The VSL for a standard log-wage equation is calculated using the following equation: ${ }^{114}$

$$
V S L=B_{2} * \text { Average Wage } * 2,000 * 100,000
$$

Here, $B_{2}$ represents the estimated coefficient for the fatality rate variable, the average wage is the average hourly wage for the sample, 2,000 assumes a forty-hour workweek, and 100,000 normalizes the VSL since the fatality rate is measured per 100,000 workers. Using this formula, the VSL in Table 3 for all workers is estimated at $\$ 9.6$ million in 2007 and $\$ 10.7$ million in 2015. These results align with VSL estimated for 2003 in Hersch and Viscusi (2010), which was $\$ 9.9$ million using the industry fatality rate measure. ${ }^{115}$

113 Id. at 767

114 Gentry \& Viscusi, supra note 51, at 93.

115 See, e.g., Hersch \& Viscusi, supra note 5, at 763. 
Table 3: Log-Wage Regressions Based on Industry Fatality Rates, All Immigrants $^{116}$

\begin{tabular}{lcc}
\hline VARIABLES & $(1)$ & $(2)$ \\
\hline \multirow{2}{*}{ Fatality Rate } & 2007 & 2015 \\
& & \\
Immigrant $x$ Fatality Rate & $0.0029^{* *}$ & $0.0028^{* *}$ \\
& $(0.0004)$ & $(0.0006)$ \\
Immigrant & $-0.0049^{* *}$ & $-0.0062^{* *}$ \\
& $(0.0009)$ & $(0.0011)$ \\
& $-0.0167^{*}$ & $-0.0162^{*}$ \\
Wage & $(0.0071)$ & $(0.0074)$ \\
& & \\
Value of Statistical Life (\$ Millions) & $\$ 16.61$ & $\$ 19.04$ \\
& $\$ 9.6$ & \\
Observations & 610.7 \\
R-squared & 66,872 & 60,800 \\
\hline
\end{tabular}

Table 3 also shows that immigrants are not compensated for job risks because the coefficient on the interaction term, Immigrant $x$ Fatality Rate, is negative and statistically significant. This means that the VSL for immigrants is negative. To illustrate, first note that calculating the VSL with an interaction term is similar to calculating the VSL from the standard log-wage equation. Here, the relevant formula is

$$
V S L=\left(B_{2}+B_{4}\right) * \text { Average Wage } * 2,000 * 100,000{ }^{117}
$$

Because $0.0019+(-0.0036)$ is less than zero, the estimated VSL for immigrants is negative, which violates standard economic theory. 118 Accordingly, we instead estimate the amount of money that immigrants lose because they are not compensated for job risks relative to native workers. To do this, first note that all workers receive compensation equal to the average fatality rate multiplied by the VSL:

$$
\text { Total Compensation }=\text { VSL } * \text { Fatality Rate }
$$

Applying this formula to the most recent data from 2015, we estimated that the VSL for all workers was approximately $\$ 10,700,000$, and the average fatality rate, using industry as the index, was 3.5 deaths

116 The totals and calculations of fatal injury data were generated by researchers at Vanderbilt University with restricted access to the CFOI research file. U.S. Bureau of Labor Statistics, supra note 61. Standard errors in parentheses: ${ }^{* *} \mathrm{p}<0.01,{ }^{*} \mathrm{p}<0.05,+$ $\mathrm{p}<0.1$.

117 Hersch \& Viscusi, supra note 5, at 761.

118 W. Kip Viscusi \& Clayton Masterman, Anchoring Biases in International Estimates of the Value of a Statistical Life, 54 J. RisK \& UNCERTAINTY 103, 104 (2017). 
per 100,000 workers. Therefore, all workers received annual compensation of $\$ 374.50$ in hazard pay. Our results in Table 3, however, show that immigrants did not enjoy this level of compensation. In fact, these results show that immigrants were underpaid by $\$ 505$ for work in dangerous jobs relative to what they would have been paid in jobs without any fatality risk. ${ }^{119}$ This type of result would not be plausible if immigrants had broad access to these safer jobs. Summing together the compensation for natives with immigrants' lost wages shows that there is an $\$ 880$ gap between native workers and immigrants in the average amount of compensation for occupational fatality risks.

Next, to test how Mexican immigrant workers fared, we divided immigrant workers into two groups: Mexican and non-Mexican immigrants. Table 4 presents estimates of the key risk and immigrant status variables for these two groups. To understand the differential impact of risk on Mexican and non-Mexican immigrant workers, we interact each measure of the fatality rate with whether a worker is a Mexican immigrant or whether the worker is a non-Mexican immigrant. Thus, we end up with two interaction terms: Mexican Immigrant $x$ Fatality Rate and non-Mexican Immigrant $x$ Fatality Rate. 120

Table 4 shows the coefficient on the industry fatality rate variable is positive and statistically significant. This yields a positive VSL for all workers of $\$ 9.4$ million in 2007, and $\$ 11$ million in 2015. Again, these results align with the VSL estimated for 2003 in Hersch and Viscusi (2010), which was $\$ 9.9$ million using the industry fatality rate measure.121 Using the same methodology as before and focusing on 2015 , this means that all workers received \$385 in hazard pay. Mexican immigrants do not receive hazard pay, however. Across all three years, the interaction term Fatality Rate * Mexican Immigrant is negative and statistically significant, indicating that Mexican immigrants receive lower compensation for their fatality risk. In 2015, this amounted to $\$ 932$ in lost pay. Non-Mexican immigrants fared better, however. The coefficient on their interaction term was only negative and statistically significant in 2015 , but this immigrant group still lost $\$ 189$ as a result of their failure to receive hazard pay.

119 This calculation requires estimating a negative VSL for immigrants. This negative VSL was approximately equal to negative $\$ 12.9$ million in 2015 . The average fatality rate for immigrants was 3.9 deaths per 100,000 workers.

120 This is an accepted practice in the VSL literature. See, e.g., Hersch \& Viscusi, supra note 5 , at 767 .

121 See, e.g., Hersch \& Viscusi, supra note 5, at 763. 
Table 4: Log-Wage Regressions Using Industry Fatality Rates, Comparing Mexican and non-Mexican Immigrants ${ }^{122}$

\begin{tabular}{lll}
\hline & $(1)$ & $(2)$ \\
VARIABLES & 2007 & 2015 \\
\hline Fatality Rate & & \\
& $0.0029^{* *}$ & $0.0029^{* *}$ \\
Mexican Immigrant $x$ Fatality Rate & $(0.0004)$ & $(0.0006)$ \\
& $-0.0075^{* *}$ & $-0.0077^{* *}$ \\
Mexican Immigrant & $(0.0012)$ & $(0.0015)$ \\
& -0.0094 & -0.0074 \\
Non-Mexican Immigrant $x$ Fatality Rate & $(0.0112)$ & $(0.0117)$ \\
& -0.0016 & $-0.0045^{* *}$ \\
Non-Mexican Immigrant & $(0.0013)$ & $(0.0016)$ \\
& $-0.0257^{* *}$ & $-0.0223^{* *}$ \\
& $(0.0082)$ & $(0.0086)$ \\
Wage & & 19.04 \\
Value of Statistical Life (Millions) & $\$ 16.61$ & \\
Observations & & $\$ 11.0$ \\
R-squared & $\$ 9.4$ & 60,800 \\
\hline
\end{tabular}

Overall, the results developed in this Section pair with those developed earlier in the paper to show that immigrants, particularly those from Mexico, fare quite poorly in the labor market. Immigrants experience higher workplace fatality risks, do not always move to safer jobs over time, and do not receive hazard pay to compensate them for job risks.

122 The totals and calculations of fatal injury data were generated by researchers at Vanderbilt University with restricted access to the CFOI research file. U.S. Bureau of Labor Statistics, supra note 61. Standard errors in parentheses: ${ }^{* *} \mathrm{p}<0.01,{ }^{*} \mathrm{p}<0.05,+$ $\mathrm{p}<0.1$. 


\section{DISCUSSION}

The previous Parts empirically demonstrated that immigrant workers in the United States often suffer in the labor market, particularly compared to their native peers. This Part leverages those results to comment on the efficacy of past OSHA programs designed to improve immigrant workplace safety and informs our policy recommendations for ways in which OSHA can further improve immigrant welfare on the job site. Section A of this Part describes immigrant outreach programs conducted by the OSHA under the Bush, Obama, and Trump Administrations. Section B then assesses the efficacy of these policies in light of the empirical conclusions reached in the previous Parts. Finally, Section C outlines one modest and one more ambitious policy proposal that OSHA could adopt to improve immigrant-worker outcomes in the labor market.

\section{A. OSHA Policies}

OSHA's organic statute directs the agency to protect all workers in the workplace. The Occupational Safety and Health Act of 1970 states in its preamble that OSHA's goal is to "assure safe and healthful working conditions for working men and women."123 OSHA's statutory charge includes immigrants, yet there has long been a perception that immigrant workers, particularly Hispanic workers, fare worse than native workers in terms of workplace safety. ${ }^{124}$ This is all the more concerning given that immigrants compose about 17 percent of the workforce and work in some of the most dangerous jobs in the country. ${ }^{125}$

In fulfillment of its organic statute, OSHA has undertaken immigrant outreach programs under the Bush and Obama Administrations, and to a lesser extent under the Trump Administration, to improve immigrant workplace safety. This Section first details some of these outreach programs before outlining some of the guidance documents and regulations that OSHA has promulgated to encourage employers to provide safety training in a language that their workers can understand.

12329 U.S.C. $\S 651$.

124 See, e.g., Henshaw, supra note 10; Hersch \& Viscusi, supra note 5, at 794-51; Loh \& Richardson, supra note 7, at 42.

125 See supra Section II.C. 


\section{Immigrant Outreach Programs}

The Occupational Health and Safety Administration is tasked with "assuring safe and healthful working conditions for working men and women," 126 and has the statutory authority to promulgate rules and regulations to protect worker safety. OSHA's statutory charge includes immigrants, 127 yet immigrant workers, particularly Hispanic workers, face higher workplace risks than native workers. ${ }^{128}$ This phenomenon has not escaped OSHA's attention, and we next provide an overview of some of the OSHA initiatives and policies that have been put in place to address immigrant safety in the workforce.

In 2002, then-Assistant Secretary of Labor for OSHA John Henshaw released a statement lamenting the number of deaths in the workforce, including the fact that Hispanic and Latino workers, many of them immigrants, bore a disproportionate share of those deaths. ${ }^{129}$ Recognizing this problem, Secretary Henshaw announced that OSHA was creating a number of programs to reduce the number of fatal workplace injuries among non-English speaking workers, particularly Hispanic or Latino workers. ${ }^{130}$ These programs included creating a Hispanic Workers Task Force, establishing an 800 number for Spanishspeaking individuals, initiating a national clearinghouse for training programs in Spanish, creating a Spanish-language website for employees and employers, and compiling a list of fluent Spanishspeaking employees across OSHA.131 In addition to creating the Task Force, OSHA also used safety and health training grants to establish training programs for non-English speaking employees and employers that hire non-English speakers. These programs were designed to reduce fatalities among the non-English speaking workforce. ${ }^{132}$

During this time, OSHA also engaged in state and local outreach programs to address immigrant fatalities. For instance, the Agency distributed a number of educational tools written in Spanish throughout Florida, such as a poster depicting four major construction hazards and a packet explaining the dangers of overhead power lines. ${ }^{133}$ In Fort Worth, OSHA also provided a ten-hour course on construction safety in

\footnotetext{
12629 U.S.C. $§ 651$.

127 See Henshaw, supra note 10.

128 Hersch \& Viscusi, supra note 5, at 749.

129 Henshaw, supra note 10.

130 Id.

131 Id.

132 Id.

133 Id. The agency also offered two ten-hour construction classes in the Fort Lauderdale area after teaming up with a Florida consulting company that specializes in safety and health advice to small business. Id.
} 
Spanish, and the Fort Worth OSHA office worked with the Hispanic Chamber of Commerce to coordinate safety courses in Spanish.134 Though these programs likely had localized successes in improving immigrant-worker safety, they were not systematically implemented on a nationwide basis. Finally, the Task Force created a clearinghouse for Spanish safety and health training materials developed by others on the OSHA website. ${ }^{135}$

OSHA's policies toward immigrant workers in the early 2000s were also the subject of Congressional oversight. In 2003, the Department of Labor released a report called "Evaluation of OSHA's Handling of Immigrant Fatalities in the Workplace" at the request of Senator Charles E. Schumer. ${ }^{136}$ This report addressed how OSHA had been addressing immigrant workplace fatalities and focused on four questions: (1) how did OSHA keep track of immigrant fatalities, (2) what resources did OSHA allocate to investigating those deaths, (3) what resources does OSHA allocate to enforce workplace rules in industries that primarily employ immigrants, and (4) how can OSHA prevent more immigrant deaths?137 Regarding tracking immigrant workplace fatalities on the job, the DOL found that OSHA's inspection priorities and reporting requirements did not distinguish between immigrant and nonimmigrant workers. ${ }^{138}$ Addressing the question regarding the resources OSHA allocated to investigating deaths, OSHA issued a memorandum directing its investigators to begin collecting information about workers' ethnicity and language capabilities so that the Agency could better track immigrant versus non-immigrant fatalities. ${ }^{139}$ To address the third question asking what resources OSHA used to investigate industries that primarily employ immigrants, OSHA was unable to provide the information needed to determine the resources allocated to industries that primarily employed immigrants since the Agency did not specifically target those industries. ${ }^{140}$ Finally, with regard to how OSHA can reduce immigrant deaths, the Report directed OSHA to do more than just engage in Hispanic outreach efforts. ${ }^{141}$ For instance, the report stated that even though OSHA's regional offices translated training

134 Id.

135 Henshaw, supra note 10.

136 OfFice of THE InSPECTOR Gen., Dep't of LABOR, Report No. 21-03-023-10-001, Evaluation OF OSHA'S HANDLING OF IMMIgRANT FATALITIES IN THE WoRKPLACE iii (2003), https://www.oig.dol.gov/public/reports/oa/2003/21-03-023-10-001.pdf.

137 Id.

138 Id.

139 Id. at iv.

140 Id.

141 Id. 
materials based on their knowledge of their region's needs, they did not have a systematic process for doing so, and therefore could not systematically determine which languages and what literacy levels their documents needed to be translated into. ${ }^{142}$

Finally, to help prevent further workplace fatalities, the report made several recommendations as to OSHA's handling of immigrant workplace fatality investigations. ${ }^{143}$ For instance, the Report recommended that OSHA ensure that its staff has sufficient second-language capability and that the Agency issue an Interpretation Letter clarifying that OSHA's "training provisions require employers to provide training in a manner that employees understand," after taking into account the employee's particular language abilities. ${ }^{144}$ The Report also recommended that OSHA examine the deterrent effect of increasing fines for willful violations that result in deaths. ${ }^{145}$

These examples from the early 2000s are not exhaustive, but they do illustrate that OSHA has long been concerned with reducing job risks to immigrant workers, and this concern did not decrease under the Obama administration. In April 2010, OSHA hosted the National Action Summit for Latino Worker Health \& Safety. ${ }^{146}$ The Summit developed an agenda to address and prevent injuries and deaths among Hispanic and Latino workers, many of whom are immigrants. ${ }^{147}$ The Summit joined together more than five hundred people, including workers and representatives from labor unions, community organizations, employer associations, and government officials, to discuss ways to reduce Latino workplace fatalities, particularly in the construction industry, which is highly dangerous and employs a large number of Latino workers. ${ }^{148}$ Follow-up summits and educational conferences were held in each OSHA region to build on the ideas developed in the national OSHA summit. ${ }^{149}$ Each of the summits was focused on providing vulnerable worker populations-such as immigrant populations-with education, training, and assistance. 150

\footnotetext{
142 OFFICE OF THE INSPECTOR GEN., supra note 136, at iv.

143 Id. at v.

144 Id.

145 Id.

146 Press Release, Dep't of Labor, U.S. Secretary of Labor to Convene National Action Summit on Latino Worker Safety and Health (Mar. 18, 2010), https://www.osha.gov/ archive/latinosummit/index.html.

147 Id.

148 Id.

149 Quick Takes, Occupational SAFEty And Health Admin. (Dec. 1, 2020), https://www.osha.gov/quicktakes/12012010.

150 Id.
} 
Finally, immigration policy has certainly been at the forefront of the Trump Administration's agenda. While there have been no major OSHA initiatives to address immigrant workplace fatalities, OSHA has maintained some immigrant outreach programs under the Trump administration. For instance, the OSHA website lists training resources in Spanish for those that work in the construction industry. ${ }^{151}$ OSHA's website also provides Spanish-language compliance assistance resources for employers. ${ }^{152}$ In addition, some OSHA regions have continued to engage in outreach programs with immigrant workers. OSHA Region VI-which includes Texas, New Mexico, Louisiana, Oklahoma, and Arkansas-partnered with the Workers Defense Project in Austin, Texas, to distribute safety materials to immigrant workers. ${ }^{153}$ OSHA Region VI also offered eleven "in-take nights" to provide Hispanic workers with an opportunity to ask questions and file complaints with OSHA. ${ }^{154}$

Immigrant workers have been a focus of OSHA's attention for nearly two decades. Yet a comprehensive understanding of how immigrant workers fare in the workplace is lacking in the legal literature. This paper fills that gap, and in doing so also offers evidence that OSHA's efforts over time have not reduced immigrant workplace fatalities.

\section{Language Training Requirements}

In addition to outreach programs to train immigrant workers directly in workplace dangers, OSHA has also, to some extent, mandated that employers train immigrant workers in a language that they can understand. Broadly, the Agency has issued guidance that employers must provide training in a language that employees can comprehend. 155 This requirement has been enforced in court. In Modern Continental Construction Company, Inc. v. OSHRC, the Court of Appeals for the First Circuit upheld an OSHA penalty against an employer who failed to train

151 Training Resources in Spanish Language, Occupational SAFETy AND HeAlth Admin., https://www.osha.gov/dte/outreach/construction_generalindustry/spanish_training. html (last visited Jan. 13, 2020).

152 Spanish-Language Compliance Assistance Resources, OccuPATIONAL SAFETY AND HEALth Admin., https://www.osha.gov/complianceassistance/index-hispanic (last visited Jan. 13, 2020).

153 Region 6 - Annual Alliance Report, Occupational Safety and Health Admin., https://www.osha.gov/alliances/regional/region6/alliance-annual-report_20190726 (last visited Jan. 13, 2020).

154 Id.

155 Memorandum from David Michaels, Assistant Sec'y for Occupational Safety and Health, to Reg'l Adm'rs (April 28, 2010), https://www.osha.gov/dep/standards-policystatement-memo-04-28-10.html. 
its employees in safety procedures that could have prevented an accident when the employer only provided training materials in English "despite a large number of employees with limited English proficiency." 156

In some settings, OSHA has also promulgated regulations that require employers to post warning signs or provide training in a language that workers can understand. For instance, OSHA mandates that safety signs that warn workers of hazards "shall be understandable to all employees who may be exposed to the identified hazard."157 In other words, OSHA requires warning signs to be posted in a language or manner that non-English speakers can comprehend and act on. Similarly, OSHA requires employers in the logging industry to "assure that all training materials used are appropriate in content and vocabulary to the educational level, literacy, and language skills of the employees being trained." 158

These multilingual signage or training requirements do not extend to all settings, however. ${ }^{159}$ For instance, OSHA currently requires that employers with workers that may be exposed to hazardous chemicals in the workplace must prepare and implement a written Hazard Communication Program and provide Safety Data Sheets, training, and labeling. 160 The OSHA website also highlights hazard communication requirements as key to preventing workers from injuring themselves with harmful chemicals. 161 These regulations were last amended in 2013 and currently do not mandate that hazard labels be in any language other than English, ${ }^{162}$ although OSHA guidance stresses that if employees receive job instructions in a language other than English, the

156 Modern Cont'l Const. Co. v. Occupational Safety \& Health Review Comm'n, 305 F.3d 43, 52 (1st Cir. 2002).

15729 C.F.R. $\S 1910.145(f)(4)(i v)(2021)$

15829 C.F.R. § 1910.266(i)(9) (2021).

159 See, e.g., Occupational Safety and Health Admin., Training Requirements in OSHA STANDARDS (2015), https://www.osha.gov/Publications/osha2254.pdf (collecting training requirements across dozens of OSHA rules and showing that few of the rules include requirements that training occur in a language workers can understand).

16029 C.F.R. $\S 1910.1200(a)(1)$.

161 Compliance Assistance Quick Start, Occupational SAFety and Health Admin., https://www.osha.gov/dcsp/compliance_assistance/quickstarts/construction/index.h tml\#step2 (last visited Feb. 1, 2020).

16229 C.F.R. § 1910.1200(f)(10) (2021) ("The employer shall ensure that workplace labels or other forms of warning are legible, in English, and prominently displayed on the container, or readily available in the work area throughout each work shift. Employers having employees who speak other languages may add the information in their language to the material presented, as long as the information is presented in English as well."). 
training and information conveyed under the Hazard Community Standard must also be in the worker's language. 163

OSHA also has several training regulations to address dangers in the construction industry, but few of these expressly require training to take place in a language the worker can comprehend. For example, OSHA requires that employers in the construction industry "shall have each employee who performs work while on a scaffold trained by a person qualified in the subject matter to recognize the hazards associated with the type of scaffold being used and to understand the procedures to control or minimize those hazards." 164 This regulation does not require this training to take place in a language that the employee can understand, however. Falls are another common cause of death in the construction industry, and OSHA requires employers to provide a training program for "each employee who might be exposed to fall hazards," 165 though this regulation does not impose any languagebased training requirements. 166

In sum, OSHA's training requirements span many industries and address numerous jobsite risks. But few of these regulations expressly require employers to train their employees in a language that they can understand. Indeed, these requirements do not even require training in Spanish despite the prevalence of Spanish-speaking workers in highrisk trades.

\section{B. Assessing OSHA's Policies}

The empirical results developed in this Article can shed light on the past efficacy of OSHA's policies to improve immigrant welfare in the workplace. Before assessing OSHA's programs, however, we highlight several key contributions to the literature. First, we constructed fatality rates using some of the most recent 2015 CFOI data to show that immigrant workers, particularly those from Mexico, continued to have a higher fatality rate than native-born workers. Second, we are the first researchers to use the NIS to provide a longitudinal assessment of whether new immigrants to the United States transition into safer jobs over time. We showed that even though some immigrants certainly improved in terms of their job safety between 2003 and 2007, a substantial portion of immigrant workers either remained in high-risk

163 Frequently Asked Questions: Hazard Communication (HAZCOM), OccupationaL SAFETY AND HEALTH ADMIN, https://www.osha.gov/html/faq-hazcom.html\#faq6 (last visited Feb. 1, 2020).

16429 C.F.R. § 1926.454(a) (2021).

16529 C.F.R. § 1926.503(a)(1) (2021).

166 See id. 
jobs during this time or moved into even more dangerous occupations. Finally, we used the latest data from the CFOI and the CPS to show that, unlike native-born workers, immigrant workers did not receive hazard pay for workplace fatality risk. This phenomenon was particularly striking for immigrant workers from Mexico. Indeed, though nativeborn workers earned between $\$ 375$ and \$385 in annual compensation for job risks in 2015 , immigrant workers were underpaid by $\$ 505$, and immigrants from Mexico were underpaid by $\$ 932.167$

In conjunction, these results shed light on ways in which OSHA can implement its policies to improve workplace safety for immigrant workers. Under the Bush Administration, OSHA began to provide Spanish-speaking immigrant workers with Spanish-language resources. OSHA established an 800 number for Spanish-speaking workers and created a clearinghouse of Spanish-language safety materials online.168 OSHA also engaged in some proactive outreach programs at that time as well through the Hispanic Worker's Taskforce. ${ }^{169}$ But our results suggest that more ambitious outreach programs are needed to reduce immigrant fatality rates relative to those of native-born workers or enable immigrant workers to receive hazard pay. ${ }^{170}$ Table 1 shows that the native fatality rates, like those for immigrant workers, remained largely unchanged under the Bush Administration. ${ }^{171}$ This stability indicates that opportunities remain for policies to address the fatality rate gap.

OSHA also engaged in outreach programs with immigrant workers under the Obama Administration. One notable Obama-era OSHA policy was the National Action Summit for Latino Worker Health \& Safety, which joined together nearly five hundred labor union leaders, community organizers, industry members, and government officials to design programs that would provide immigrant communities with education, training, and assistance. ${ }^{172}$ Although programs like this almost certainly helped reduce immigrant fatalities, even ambitious conferences do not necessarily translate into policies that substantially improve immigrant-worker safety. We showed that the fatality rate for immigrants was higher than U.S.-born workers in 2007 and 2015 and that immigrants, especially those from Mexico, did not receive hazard

\footnotetext{
167 See supra Section V.D.

168 See supra Section VI.A.

169 Id.

170 See supra Section III.C.

171 See supra Section III.C.

172 See supra Section VI.A.
} 
pay for bearing these risks. ${ }^{173}$ Immigrant fatality rates did not improve relative to those of native-born workers between 2007 and 2015, indicating that more ambitious policy efforts are needed to improve immigrant workers' safety at the job site.

\section{Policy Proposals}

We offer two proposals that OSHA could implement to improve workplace safety for immigrant workers. First, we recommend that OSHA, subject to a benefit-cost test, should provide immigrant workers with safety materials in their native languages whenever the Agency engages in outreach programs to improve immigrant safety. Prior research has shown that immigrants lacking English proficiency face especially high job risks and fail to receive hazard pay relative to native workers or other immigrant groups. ${ }^{174}$ Communicating risks and safety precautions in Spanish, or the immigrant's native language, could have significant returns in terms of workplace safety for immigrant workers that lack English proficiency. Thus, our more modest proposal recommends that OSHA identify which of its outreach programs most efficiently identifies an immigrant worker's native language so that OSHA can distribute safety materials in that language.

Our more ambitious proposal recommends that OSHA promulgate regulations requiring employers of non-English speaking workers to translate all safety materials - whether those be chemical labels, safety data sheets, or training manuals-into a language the worker can comprehend whenever the benefits of doing so exceed the costs. To be sure, we recognize that OSHA currently has a broad guidance policy that employer's train employees in a language their employees can understand along with requirements that mandate multilingual training in some circumstances-such as the requirement that some safety signs be posted in a language that workers comprehend, ${ }^{175}$ or that training programs in the logging industry are conducted in a worker's native language. ${ }^{176}$ These multilingual training requirements are not universal, however. As we note in Section VI.A, risks posed by hazardous chemicals, along with training related to scaffolding or falls in the construction industry, do not expressly need to be conveyed in a language that workers can understand. ${ }^{177}$

\footnotetext{
173 See supra Section III.C.

174 Hersch \& Viscusi, supra note 5, at 768.

175 29 C.F.R. § 1910.145(f)(4)(iv) (2021).

17629 C.F.R. $\$ 1910.266(\mathrm{i})(9)$ (2021).

17729 C.F.R. § 1926.454(a) (2021); 29 C.F.R. § 1926.503(a)(1) (2021).
} 
Accordingly, we recommend that OSHA conduct a benefit-cost analysis to determine when to promulgate regulations mandating that employers provide multilingual safety and training materials. One regulation likely to pass a benefit-cost test is mandating that employers provide training or safety materials in Spanish. Here, the benefits include lives saved and injuries averted from the Spanish-language safety materials, while the costs will be primarily driven by compliance costs for employers. Of course, these regulations can be tailored as needed to particular industries or occupations that employ a large portion of Spanish-speaking workers to minimize unnecessary compliance costs. Next, looking beyond Spanish-language requirements, it is likely that OSHA regulations for other languages could also pass a benefit-cost test for dangerous occupations that employ large numbers of non-English and non-Spanish speaker workers. We accordingly recommend that OSHA investigate which occupations those may be and promulgate regulations accordingly. Finally, as a safety valve to minimize compliance costs, we suggest that OSHA include a provision in its regulations that employers need not hire workers with whom they cannot communicate. This would ensure that small employers could comply with OSHA's regulations without putting immigrant workers at risk.

Overall, our proposed regulatory scheme would encourage employers to provide training manuals, chemical warnings, and verbal training in a language that workers can comprehend and act on. By educating immigrant workers about job risks, these workers are better able to select jobs that will compensate them for those risks or transition into safer jobs with lower fatality rates. As a result, immigrant workers can become safer, and the gap between immigrant and worker fatality rates can begin to close.

\section{CONCLUSION}

Immigrant workers composed between 10 and 15 percent of the workforce between 2003 and 2015 and make up a significant portion of workplace fatalities. 178 OSHA is tasked with improving safety for all workers, including immigrants, and OSHA has undertaken a number of initiatives directed specifically at immigrant job safety. ${ }^{179}$ But despite these programs, we show that immigrants still suffer in the workplace in a number of ways: they have higher average fatality rates than native workers, remain trapped into dangerous jobs over time, and do not

178 See supra Section III.B.

179 See supra Section VI.A. 
receive compensation for job risks. These results have implications for OSHA. Though OSHA's programs under the Bush and Obama Administrations certainly improved workplace safety for many immigrants, we suggest that OSHA could be doing more. In particular, given prior research showing the importance of English proficiency in receiving hazard pay, ${ }^{180}$ we recommend that OSHA focus on providing safety materials to immigrants in the immigrant's native language. Alternatively, OSHA could take a more aggressive stance and promulgate regulations mandating that employers also provide training and safety materials in Spanish when the benefits of doing so exceed the costs.

180 Hersch and Viscusi, supra note 5, at 768. 
982

[Vol. 51:933

APPENDIX

This Appendix first includes summary statistics for the CPS sample used to conduct our regression analysis in Appendix Table 1.

Appendix Table 1: Current Population Survey Summary Statistics

\begin{tabular}{|c|c|c|c|c|}
\hline \multirow[b]{2}{*}{ VARIABLES } & \multicolumn{2}{|c|}{2007} & \multicolumn{2}{|c|}{2015} \\
\hline & Mean & $\begin{array}{l}\text { Standard } \\
\text { Deviation }\end{array}$ & Mean & $\begin{array}{l}\text { Standard } \\
\text { Deviation }\end{array}$ \\
\hline Wage (Dollars/Hour) & 16.6 & 9.9 & 19.0 & 11.9 \\
\hline Experience & 22 & 12.2 & 22.4 & 12.7 \\
\hline Education & 12.5 & 2.6 & 12.8 & 2.7 \\
\hline Age & 39.5 & 12.0 & 40.19 & 12.5 \\
\hline Union (Percent) & 14.8 & 35.6 & 12.8 & 33.4 \\
\hline Government (Percent) & 12.6 & 33.2 & 12.2 & 32.7 \\
\hline Hispanic (Percent) & 17.5 & 38 & 18.8 & 39 \\
\hline Immigrants (Percent) & 18.9 & 39.2 & 18.9 & 39.1 \\
\hline Mexican Immigrants (Percent) & 8.1 & 27.2 & 7.5 & 26.4 \\
\hline Married (Percent) & 55.2 & 49.7 & 51.1 & 50 \\
\hline White (Percent) & 81.9 & 38.5 & 79.1 & 40.6 \\
\hline Black (Percent) & 10.8 & 31 & 12.3 & 32.8 \\
\hline Native American (Percent) & 1.2 & 10.9 & 1.4 & 11.8 \\
\hline Asian (Percent) & 4.4 & 20.6 & 5.6 & 22.9 \\
\hline
\end{tabular}

